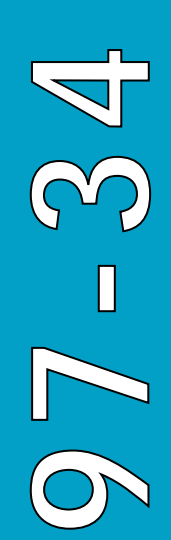

Factors Infiuencing Ice Conveyance at River Confiuences

Robert Ettema, Marian Muste, Anton Kruger, and J on Zufelt 
Abstract: This report documents preliminary findings concerning ice jam conditions in river confluences, using two laboratory approaches. First is categorizing the different conditions of ice discharge into a confluence based on two general classifications: free drift of ice and movement of contiguous ice accumulations. The variables defining ice discharge for the two categories are assembled via dimensional analysis into two consistent sets of nondimensional parameters. The categorization, together with the nondimensional parameters, is used to evaluate ice jam problems at confluences - the two most common causes of jams seem to be sluggish water velocities in the outflow channel and local bathymetric features. The second approach examines how confluence geometry and flow processes affect ice discharge - for example, the influence on ice discharge of bathymetric features. The approach uses a large hydraulic model of a two-channel confluence, which is adaptable to a variety of channels, and particle image velocimetry (PIV) for determining and mapping whole fields of water and ice velocities in a confluence. PIV, which is becoming extensively used, lends itself very well here. This study is the first demonstration of the PIV method for ice movement through a two-river confluence. It shows promise. The hydraulic model and PIV method are used in a case study of ice discharge through the confluence of the Missouri and Mississippi rivers, a confluence prone to severe ice jams.

How to get copies of CRREL technical publications:

Department of Defense personnel and contractors may order reports through the Defense Technical Information Center: DTIC-BR SUITE 0944

8725 J OHN J KINGMAN RD

FT BELVOIR VA 22060-6218

Telephone 18002253842

E-mail help@dtic.mil msorders@dtic.mil

WWW http://www.dtic.dla.mil/

All others may order reports through the National Technical Information Service: NTIS

5285 PORT ROYAL RD

SPRINGFIELD VA 22161

Telephone 17034874650

E-mail $\quad \begin{aligned} & 17034874639 \text { (TDD } \\ & \text { orders@ntis.fedworld.gov }\end{aligned}$

WWW http://www.fedworld.gov/ntis/ntishome.html

A complete list of all CRREL technical publications is available from: USACRREL (CECRL-LP)

72 LYME RD

HANOVER NH 03755-1290

Telephone 16036464338

E-mail techpubs@crrel.usace.army.mil

For information on all aspects of the Cold Regions Research and Engineering Laboratory, visit our World Wide Web site: http://www.crrel.usace.army.mil 


\section{Special Report 97-34}

US Army Corps

of Engineers $₫$

Cold Regions Research \&

Engineering Laboratory

\section{Factors Influencing Ice \\ Conveyance at River Confluences}

Robert Ettema, Marian Muste, Anton Kruger, and J on Zufelt

December 1997 


\section{PREFACE}

This report was prepared by Dr. Robert Ettema, Professor and Research Engineer, Dr. Marian Muste, Research Engineer, Dr. Anton Kruger, Research Engineer, of The University of Iowa, Iowa Institute of Hydraulic Research (IIHR), and Dr. Jon Zufelt, Research Hydraulic Engineer, Ice Engineering Division, Research and Engineering Directorate, U.S. Army Cold Regions Research and Engineering Laboratory. Funding for this work was provided by the Office of the Chief of Engineers through CWIS, Work Unit 33024, Effects of Channel Modifications on Confluence Ice Problems.

Technical review for this report was provided by Kathleen D. White and James L. Wuebben, both Research Hydraulic Engineers of CRREL's Ice Engineering Research Division. The authors were greatly assisted in the use of the PIV method by Dr. Ichiro Fujita of Gifu University, Japan.

The contents of this report are not to be used for advertising or promotional purposes. Citation of brand names does not constitute an official endorsement or approval of the use of such commercial products. 


\section{CONTENTS}

Preface

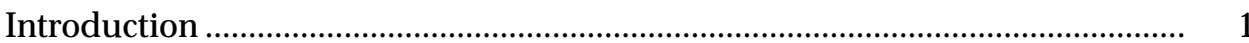

Dimensional analysis .................................................................................... 1

Categories of ice discharge through confluences ....................................... 1

Free drift of ice through river confluences ...................................................... 3

Ice-layer movement through a confluence ………........................................ 5

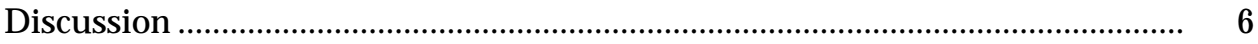

Particle image velocimetry …….................................................................. 7

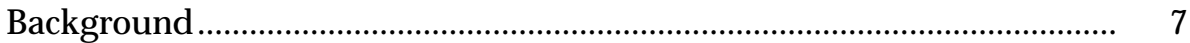

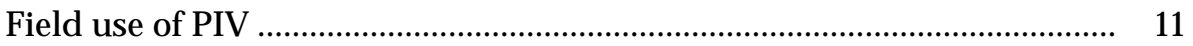

Modeling ice discharge and jamming processes in confluences ........................ 11

Ice movement through the confluence of the Mississippi and

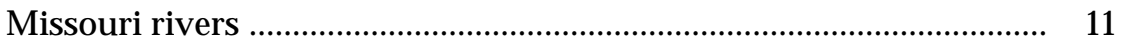

Hydraulic model configuration ............................................................. 15

PIV system for measuring water and ice velocities .................................. 17

Test procedure ................................................................................ 17

Image recording and processing ……...................................................... 17

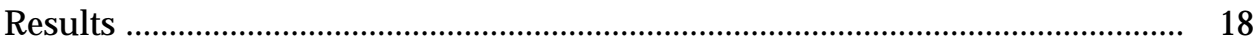

Water velocities ……............................................................................... 21

Ice velocities ................................................................................. 22

Ice transport through the confluence ........................................................... 22

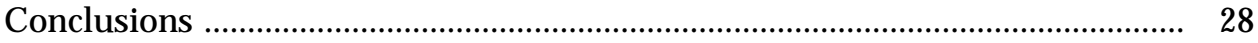

Confluence conditions causing jams ....................................................... 28

Ice discharge through the confluence of the Missouri and

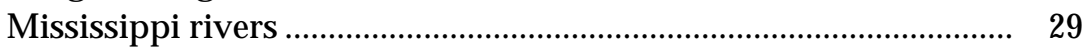

PIV for mapping ice velocities ............................................................... 29

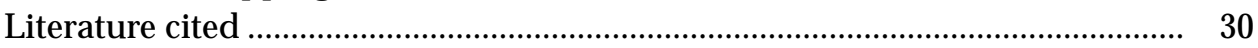

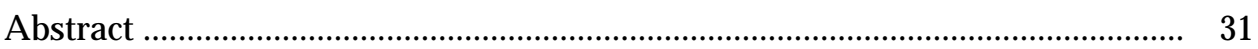

\section{ILLUSTRATIONS}

Figure Page

1. Categories of ice free-drift through a confluence ............................................. 2

2. Categories of ice-layer movement through a confluence .............................. 3

3. Variables influencing ice free-drift through a confluence ............................... 4

4. Variables influencing ice-layer movement through a confluence ................. 5

5. Typical setup used in an early PTV system for tracking individual floats on water surface ............................................................................ 8

6. Correlation algorithm used for determining ice velocities ............................. 9

7. Ice movement through a channel confluence at the Grass Island Pool of the upper Niagara River ......................................................................... 12

8. Layout of the general hydraulic model showing the model confluence of the Mississippi and Missouri rivers ....................................................... 13

9. Ice movement through the confluence of the Mississippi and Missouri

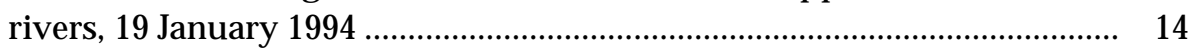

10. View of the hydraulic model's alluvial bed bathymetry ............................... 15 
11. Setup of the PIV system used in this study

12. Flow chart of principal steps in the PIV technique used in this study ......... 18

13. Correction of the field of view ............................................................. 19

14. Water surface velocities ...................................................................... 20

15. Cross-sectional distributions of the water-surface velocities shown in Figure 14c................................................................................. 21

16. Temporal variation of velocities at point $A$ in Figure 14a ............................. 22

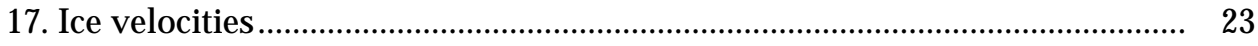

18. Cross-sectional distributions of ice velocities ................................................. 24

19. Temporal variations of ice velocity at points $B$ and $C$ in Figure $17 \mathrm{~b} \ldots \ldots \ldots \ldots . .24$

20. Two views of model ice moving through confluence of rectangular

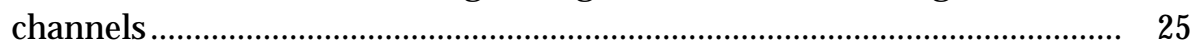

21. Model ice moving through the alluvial channel fitted with border ice ........ 26

22. Ice drifting from the Missouri River across the Mississippi River at the confluence ............................................................................................ 27

23. Effect of simulated wind over the confluence ............................................. 28

24. Tentative location of incipient jamming observed in the modeled Missouri River

\section{TABLES}

Table

1. Categories of ice movement through confluences 


\title{
Factors Influencing Ice Conveyance at River Confluences
}

\author{
ROBERT ETTEMA, MARIAN MUSTE, ANTON KRUGER, AND JON ZUFELT
}

\section{INTRODUCTION}

River confluences, the intersection and merging of two sets of water, sediment, and, in cold regions, ice discharge conditions, are prime locations for ice jam development. The potential congestion of ice forced from two channels into a single channel, together with the complex bathymetry that usually occurs there, hamper ice discharge through confluences. Fairly numerous accounts exist of ice jams at confluences. Tuthill and Mamone (1997) provide a comprehensive summary of problematic confluence sites in the U.S. The factors influencing ice jam development at river confluences, however, have not received rigorous analytical attention.

This report documents the approaches to and preliminary results of a comprehensive study of ice discharge and jamming at river confluences. It identifies the important parameters influencing the ice discharge capacity of confluences, and, as a case study, it presents a well illustrated description of ice-conveyance and jam-initiation processes in a hydraulic model of the confluence of the Missouri and Mississippi rivers. The confluence of those two rivers is well known for its ice jams.

The study entails two investigative approaches. One approach is to identify a group of influential, nondimensional parameters for use in generally describing ice discharge and jamming in river confluences. The other approach is to examine in detail the features of water flow and ice movement through a representative confluence. The first approach required a dimensional analysis of the variables most likely to affect ice discharge through a generic confluence. The second approach required the use of a hydraulic model of a confluence and the development of a sophisticated imaging process for mapping vectors of water and ice movement.

\section{DIMENSIONAL ANALYSIS}

Dimensional analysis of ice discharge through a confluence of two channels is complicated by a potentially large number of variables. These variables all may need to be considered when describ- ing ice movement in two initially separate channels that merge as a single channel through the usually complicated bathymetry of a confluence. To make the analysis feasible, the following two major approximations are made:

- Confluence geometry is treated as the intersection of two prismatic (rectangular) channels, whose widths greatly exceed their depths, thereby simplifying description of channel geometry.

- Ice discharge through confluences is categorized according to whether ice enters the confluence as a single layer of free drifting ice moving with a velocity slightly less than the water surface, or as a contiguous, thickened accumulation extending approximately across the full width of the channel, and moving with a velocity that is much less than the water velocity along the underside of the accumulation.

These approximations enable the key nondimensional, gross parameters influencing ice movement through confluences to be identified, and reduce the number of parameters needed to describe the essential processes that occur when two flows of ice merge. Other, less significant, simplifications are made subsequently in the analysis.

The analysis does not take into account the influences of such channel features as bars, large dunes, rock outcrops, etc. Nor does it include the presence of engineered features such as bridges, wharves, channel-control structures, etc. The hydrometeorological influences of air temperature (as affecting freezing consolidation of drifting ice) and wind also are neglected. These channel, engineered, and hydrometeorological factors likely are very important; however, they do not play a role in the essential process of waterborne ice discharge through the confluence of prismatic channels, which is considered in the ensuing dimensional analysis.

Categories of ice discharge through confluences Ice discharge through confluences is classified below using two general categories: free-drifting 
Table 1. Categories of ice movement through confluences.

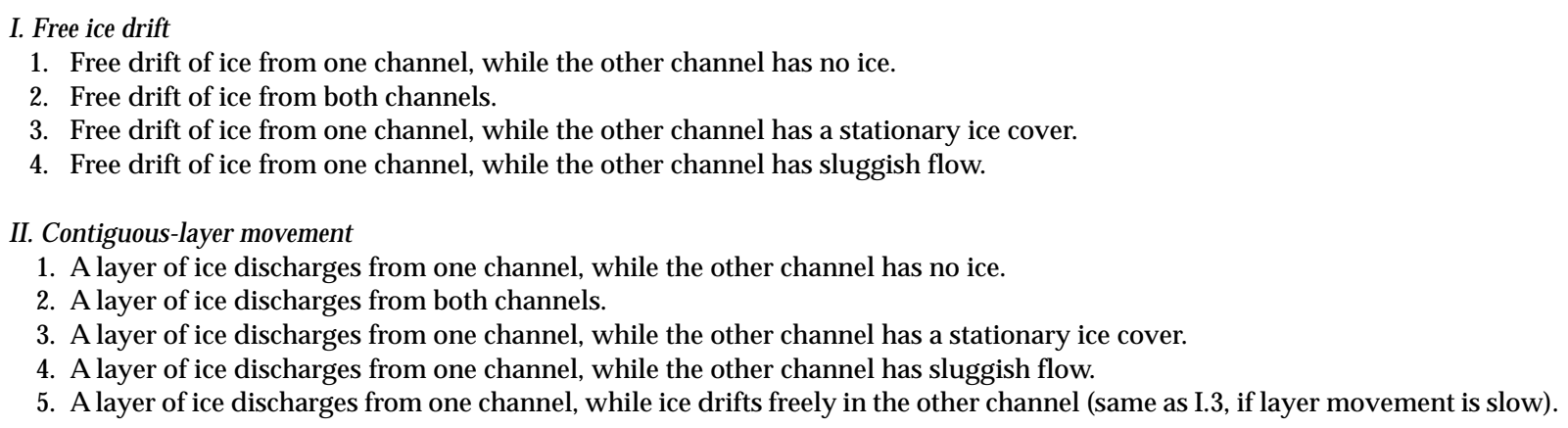

ice, and moving layers of accumulated ice pieces whose individual size is much smaller than channel size. Each category has several sub-categories in accordance with the combination of ice discharge and water flow conditions in each confluent channel.

The distinction between free-drifting ice pieces and a moving accumulation of ice is useful, because the forces propelling the ice into the confluence differ between the two situations, and therefore differences arise between the sets of parameters needed to describe the two categories. For free-drifting ice pieces, flow drag and impact forces on, as well as the inertia of, the individual pieces determine their transport into a confluence. The movements of ice accumulations, however, are influenced by the streamwise component of accumulation weight, accumulation momentum, and shear stress at the banks attributable to friction and on the underside attributable to water flow. For free drift of ice, individual ice piece size is important. It is less important in describing the behavior of an accumulation of ice, for which thickness and width are more important.

In addition, it is likely that there are differences in the way the two categories of confluent flows of ice merge. It can be envisioned, for example, that significant shoving and thickening of the confluent accumulation accompany the merging of two moving particulate accumulations. The merging of free-drifting ice pieces is likely to be less marked by shoving and thickening. Instead, areal repacking of

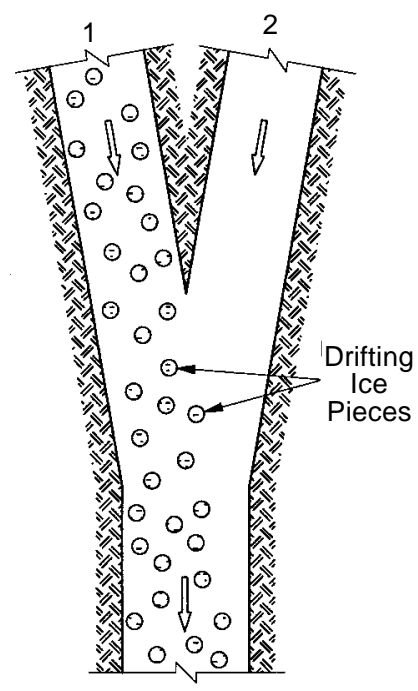

(a)

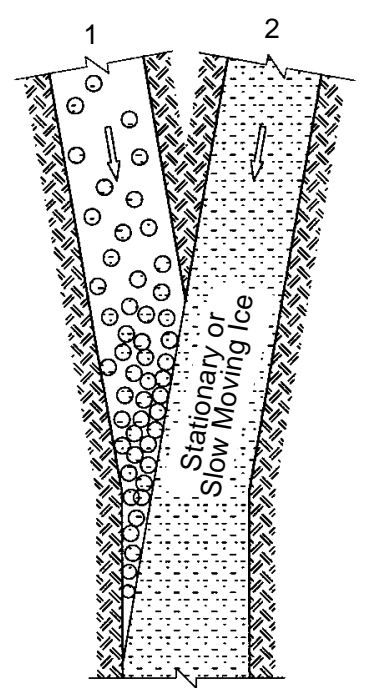

(c)

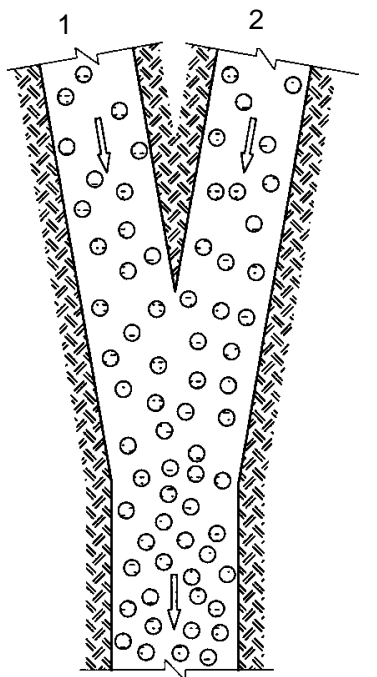

(b)

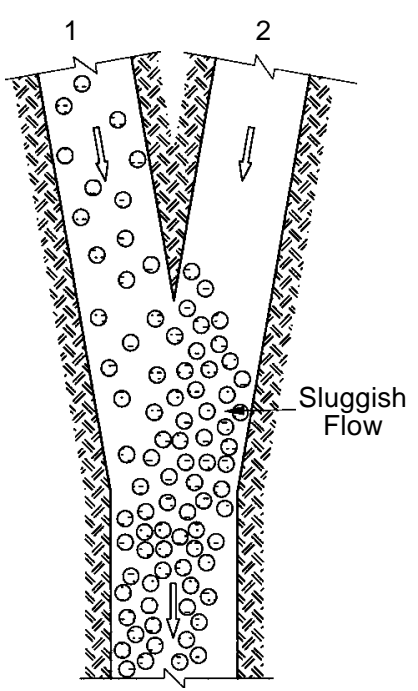

(d)
Figure 1. Categories of ice free-drift through a confluence ( $a=$ I.1; $b=I .2 ; c=I .3 ; d=I .4$ [Table 1]). 
pieces may be a characteristic feature. No doubt there is a transition between the two categories.

The free-drift and contiguous-accumulation categories can be classified into sub-categories that reflect different combinations of merging ice flows, as shown in Table 1.

The two sets of subcategories are illustrated in Figures 1 and 2. The foregoing classification does not include a further level of categorization related to the circumstances of ice movement in the stem channel downstream of the confluence; it is assumed that the condition of ice movement in the outflow channel will be the same as that in the larger confluent channel. Common examples of this situation occur when the larger confluent

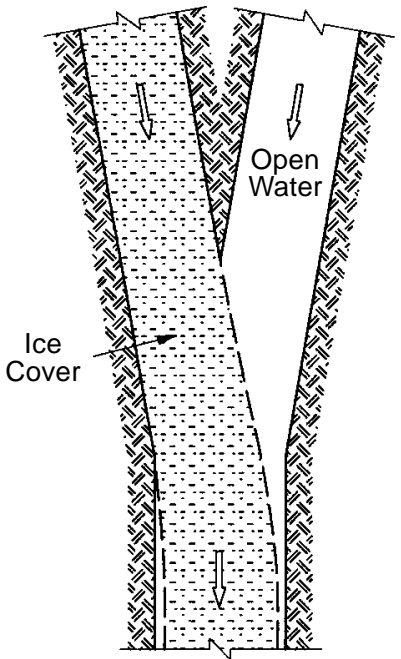

(a)

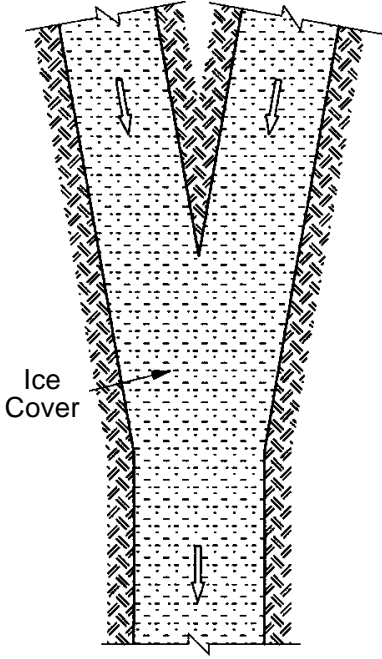

(b) channel and the outflow channel are subject to a significant backwater effect, and when one channel flows into a lake, which is the limiting condition of a channel flowing into a larger confluent channel with sluggish (or negligible) velocities.

The foregoing subcategories are intended not only to reduce the processes associated with ice discharge through confluences so that they are more readily amenable to dimensional analysis, but also to help define the actual confluence conditions for which jams are most likely. In this regard, an important issue to be addressed by this study is whether ice jams at confluences usually are attributable to limits in the capacity of the confluent prismatic channels to convey ice, or whether jams usually occur because of local channel irregularities often found at confluences (e.g., alluvial bars, flow features, channel-control structures). This point is discussed further below.

\section{Free drift of ice through river confluences}

To describe the characteristics of ice discharge and jamming at river confluences in general terms, it is necessary to establish a group of important nondimensional parameters that express the proportionate influences of water flow, ice flow, and confluence-channel characteristics. Figure 3 is a schematic illustration of the variables associated with water and ice discharge through a confluence of two fixed-bed channels of rectangular cross

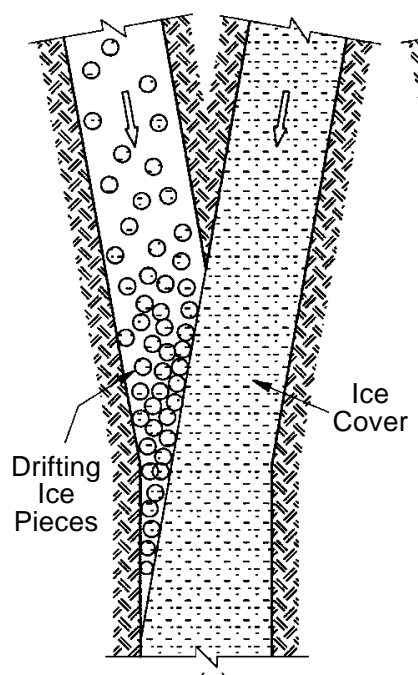

(c)

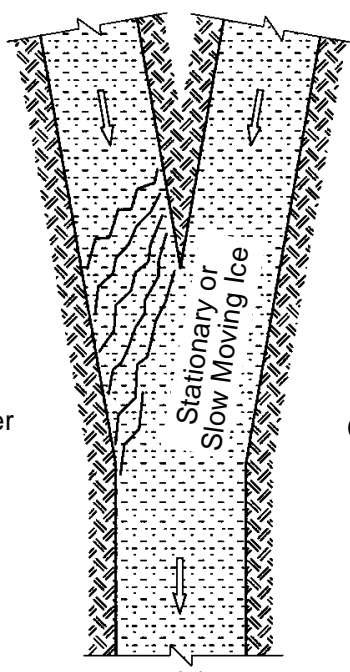

(d)

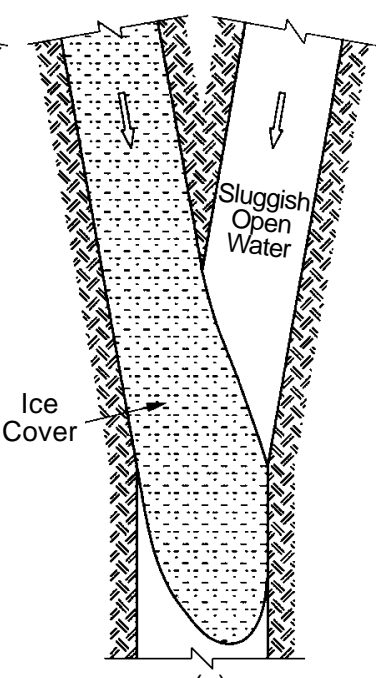

(e)
Figure 2. Categories of ice-layer movement through a confluence ( $a=I I .1 ; b=$ II. $2 ; c=I I .5 ; d=I I .3 ; e=I I .4$ [Table 1]). section. The same size ice pieces are taken to be moving through both channels. The confluent inflow channels are designated with subscripts 1 and 2 . The confluence outflow channel is designated with subscript $c$.

The discharge $Q$, unit discharge $q$, or a representative velocity $V$ of flow in one of the channels shown in Figure 3 can be described using depth $Y$, width $b$, channel slope $S$, and channel roughness $k$, i.e., by means of the Manning-Strickler equation. The terms are defined in Figure 3. Note that, in this discussion, the variables $Q, q$, or $V$ can be used (with $b, Y$, and 


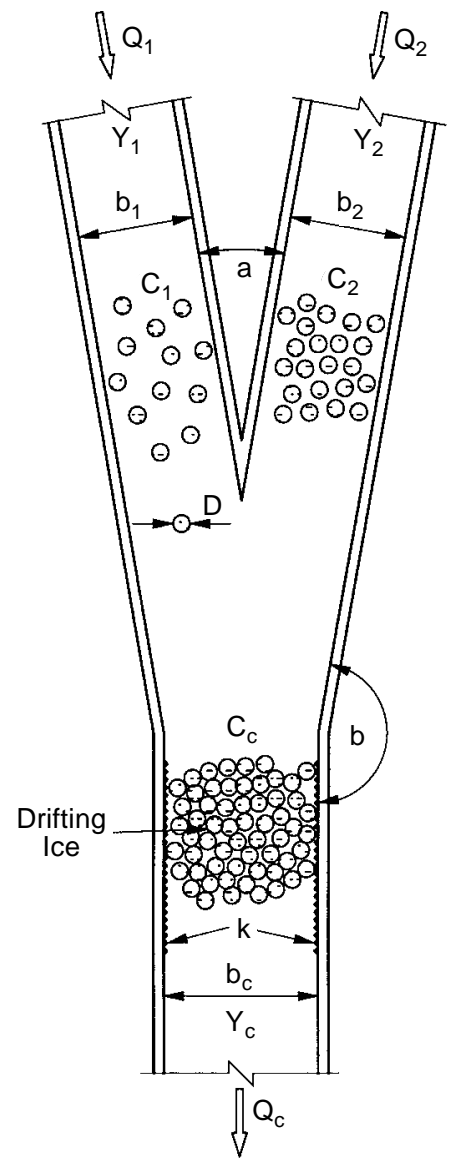

Figure 3. Variables influencing ice free-drift through a confluence.

$k$ ) instead of channel slope $S$. The present analysis uses $Q$, as it gives more meaningful parameters for describing confluent flows than do $q, V$, or $S$. The fluid properties of concern are kinematic viscosity $v$, density $\rho$, and surface tension strength $\sigma$. The ice pieces, taken to be of uniform size, are described using a characteristic plan dimension $D$, thickness $h$, density $\rho_{\mathrm{i}}$, and a friction coefficient for contact among ice pieces and with the channel banks $\mu$. The flow is driven by gravitational acceleration $g$. The discharge of free-drifting ice pieces moving at nearly the surface water velocity in a single channel can be described in terms of areal concentration $C$; ice discharge $G \approx C(h b)(Q / b Y)=C(h / Y) Q$.

A total of 13 variables are needed to describe the discharge of free-drifting ice in a channel. To describe ice discharge in two channels, which differ only in geometry and discharges of water and ice, the number of variables increases to 20; added are $Q, Y, b, k, C, D$, and $h$ for the second channel. The material properties of water and ice are taken to be the same for all channels. To describe the merging of ice flow from two channels confluent into a single outflow channel, additional variables are needed to describe the orientation of the outflow channel relative to the confluent channels, $\alpha$ and $\beta$, and the hydraulic characteristics of the outflow channel $\left(Q_{\mathrm{c}^{\prime}} b_{\mathrm{c}^{\prime}}, Y_{\mathrm{c}^{\prime}}\right.$, and $\left.k\right)$. The total number of variables is now 26 .

For the simple case of no ice jamming, continuity of water and ice discharges through the confluence gives, respectively, for water

$$
Q_{1}+Q_{2}=Q_{\mathrm{c}}+\Delta \forall / \Delta t
$$

and for ice

$$
G_{1}+G_{2}=G_{\mathrm{C}}+\Delta \forall_{\mathrm{i}} / \Delta t .
$$

In eq 1 and $2, \Delta \forall$ and $\Delta \forall_{\mathrm{i}}$ are changes in water and ice volume stored in the confluence reach during time period $\Delta t$. Up to the condition of incipient jamming in a confluence of river channels, it may be assumed that $\Delta \forall=0$ and $\Delta \forall_{\mathrm{i}}=0$. Once jamming takes place, $\Delta \forall>0$ and $\Delta \forall_{\mathrm{I}}>0$, ice inflow begins to exceed ice outflow from the confluence, and water inflow may exceed outflow.

Up to incipient jamming, eq 2 may be written simply as

$$
G_{1}+G_{2}=G_{c}
$$

or

$$
(C[h / Y] Q)_{1}+(C[h / Y] Q)_{2}=(C[h / Y] Q)_{c} .
$$

For water and ice conveyed by a river discharging into a reservoir or lake, $Q_{2}=0$ and $Q_{\mathrm{c}} \approx 0$, such that

$$
Q_{1}=\Delta \forall / \Delta t
$$

and $G_{2}=0$ and $G_{\mathrm{C}} \approx 0$, such that

$$
G_{1}=\Delta \forall_{\mathrm{i}} / \Delta t
$$

The present analysis considers incipient ice jamming at a confluence of rivers and at a river discharging into a reservoir or lake. By assuming that ice piece dimensions, $D$ and $h$, are the same for all channels, and that the channels have the same roughness $k$, the number of variables reduces to 22. If it is further assumed that the flows are subcritical, the effects of gravity $g$ are taken care of by use of an open-channel discharge relationship for 
$Q$, and by specifying that ice floats. The influence of water viscosity $v$ can be neglected if it is assumed that flow in the channels and around ice pieces is fully turbulent. For ice pieces in actual rivers, surface tension $\sigma$ is negligible. The number of variables finally reduces to 19 .

If the inflows and outflow of ice occur as a single layer of ice pieces of a given size conveyed in subcritical flow conditions, the following functional relationship may be written for the areal concentration of ice discharge on the confluence outflow channel $C_{c}$, as the dependent variable of interest:

$$
\begin{aligned}
& C_{\mathrm{c}}=f_{\mathrm{d}}\left(Q_{1}, Q_{2}, b_{1}, b_{2}, b_{\mathrm{c}}, Y_{1}, Y_{2}, Y_{\mathrm{c}}, k, D, h,\right. \\
& \left.\quad C_{1}, C_{2}, \alpha, \beta, \mu, \rho, \rho_{\mathrm{i}}\right) .
\end{aligned}
$$

Equation 7 assumes that, for a confluence of rivers, $Q_{\mathrm{c}}=Q_{1}+Q_{2}$, and for a confluence of a river and a reservoir or lake, $Q_{2}, G_{2}=0$, and eq 5 and 6 pertain. The 19 variables in eq 7 are reducible to 16 nondimensional parameters, given two basic dimensions (length and time) involved with the volumetric discharge of ice through a confluence. If a dimensional analysis is carried out using $D$, $Q_{1}+Q_{2}$, and $\rho$ as the repeating variables, the following functional relationship emerges for the limiting condition of a single layer of free-drifting ice discharging through a confluence:

$$
\begin{aligned}
C_{\mathrm{c}} & =\varphi_{\mathrm{dl}}\left(\frac{Q_{1}}{Q_{1}+Q_{2}},\left(\frac{b}{D}\right)_{1,2, \mathrm{c}},\left(\frac{Y}{D}\right)_{1,2, \mathrm{c}},\right. \\
& \left.\frac{k}{D}, \frac{h}{D}, C_{1}, C_{2}, \alpha, \beta, \mu, \frac{\rho_{\mathrm{i}}}{\rho}\right) .
\end{aligned}
$$

Equation 8 can be rearranged to relate channel widths in a more meaningful manner:

$$
\begin{aligned}
& C_{\mathrm{c}}=\varphi_{\mathrm{d} 2}\left(\frac{Q_{1}}{Q_{1}+Q_{2}}, C_{1}, C_{2}, \alpha, \beta,\right. \\
& \left.\quad \frac{b_{1}}{b_{C}}, \frac{b_{2}}{b_{C}}, \frac{b_{\mathrm{C}}}{D}, \frac{D}{h},\left(\frac{h}{Y}\right)_{1,2, C}, \frac{k}{D}, \mu, \frac{\rho_{\mathrm{i}}}{\rho}\right) .
\end{aligned}
$$

These parameters are useful for describing various confluence conditions. For example, in the simple case of a single channel entering a lake (Fig. $1 \mathrm{~d}), b_{1} / b_{\mathrm{c}} \approx 0, b_{2} / b_{\mathrm{c}}=1, \beta=180^{\circ}$, and $Q_{1} /\left(Q_{1}+\right.$ $\left.Q_{2}\right) \approx 1$. Note that eq 8 and 9 can be made more elaborate by including additional variables, such as different ice piece sizes and roughness conditions in the two confluent channels. For most confluences, the first nine parameters usually will be of far greater importance than the last parameters in eq 9. Only when the outflow channel is comparatively shallow or rough will the last parameters be important.

The effects of viscosity and surface tension become important when conducting hydraulic model tests using small pieces of model ice for simulating ice movement. Then, eq 9 should be expanded to include values of Reynolds number $Q D /(v b Y)$ and Weber number $\rho L Q^{2} /(b Y)^{2} \sigma$ for the channels.

\section{Ice-layer movement through a confluence}

Flow in a single channel with a moving ice cover (Fig. 4) can be defined using its discharge $Q$ and depth $Y$, width $b$, channel roughness $k$, and ice roughness $k_{\mathrm{i}}$. The volumetric rate of ice-accumulation discharge as a contiguous layer of ice extending across the full width of the channel and moving at a speed less than the surface water speed in a single channel can be written as a volumetric proportion $\eta$ of the water discharge bulked

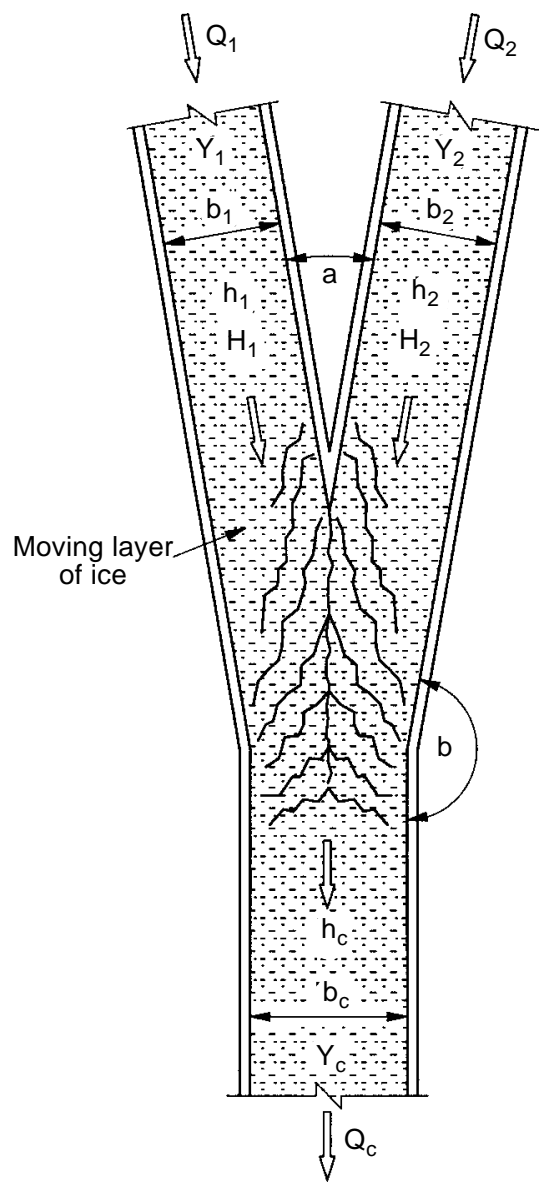

Figure 4. Variables influencing ice-layer movement through a confluence. 
commensurately with the porosity of the layer $p$, i.e., $G=\eta Q(1-p)$. The material behavior of the layer can be defined using its thickness $H$, angle of internal resistance $\phi$, porosity $p$, the density of ice $\rho_{i}$, and friction between ice and banks $\mu$. As explained above, the effects of water viscosity and surface tension can be neglected for the scale of flows in rivers. Water density $\rho$ must be retained for use with $\rho_{\mathrm{i}}$ as a variable. Therefore, a minimum of 12 variables is needed to describe the discharge of a continuous layer of ice moving in a channel. The influences of gravity, which motivate the discharge of water and ice, are accounted for in the discharge relationships for water and ice, and in the relationship between layer thickness $H$ and ice discharge rate $G$.

To describe ice discharge in two channels that differ only in geometry and the discharges of water and ice, the number of variables increases to 19 , adding, for the second channel, $Q, Y, b, k, k_{\mathrm{i}}$, $H$, and $\eta$. The material properties of water and ice, layer porosity, and friction are taken to be the same for all channels. To describe the merging of ice flow from two channels confluent into a single outflow channel, the number of variables increases with the addition of variables describing the orientation of the outflow channel relative to the confluent channels, $\alpha$ and $\beta$, and the hydraulic characteristics of the outflow channel $\left(Q_{\mathrm{c}^{\prime}}, b_{\mathrm{c}^{\prime}} Y_{\mathrm{c}^{\prime}}, k\right.$, and $\left.k_{\mathrm{i}}\right)$. The total number of variables is now 26 . The number of variables can be reduced to 22 if the roughnesses $k$ and $k_{\mathrm{i}}$ are assumed the same for each channel.

For the simple case of no ice jamming (i.e., no significant channel storage of water and ice in the confluence), continuity of water and ice discharge through the confluence, without jam formation, gives respectively

$$
Q_{1}+Q_{2}=Q_{c}
$$

and, for ice discharge

$$
G_{1}+G_{2}=G_{c}
$$

or

$$
\begin{aligned}
G & =\eta_{\mathrm{c}} Q_{\mathrm{c}}(1-p)=\eta_{1} Q_{1}(1-p) \\
& +\eta_{2} Q_{2}(1-p)
\end{aligned}
$$

with ice discharge expressed as a proportion $\eta$ of water discharge. However, for the limiting condition of incipient jamming, eq 4 pertains.

The pertinent variables may be assembled in the following functional relationship, for merging ice layers comprising ice of a given size (small compared to channel width), with ice outflow as the dependent variable:

$$
\begin{gathered}
\eta=f_{\mathrm{L}}\left(Q_{1}, Q_{2}, b_{1}, b_{2}, b_{\mathrm{c}}, Y_{1}, Y_{2}, Y_{\mathrm{c}}, k_{\mathrm{b}}, k_{\mathrm{i}},\right. \\
\left.\eta_{1}, \eta_{2}, H_{1}, H_{2}, p, \rho_{\mathrm{i}}, \rho, \mu, \phi, \alpha, \beta\right) .
\end{gathered}
$$

The 22 variables in eq 13 are reducible to 19 nondimensional parameters, given three basic dimensions (mass, length, and time) involved with ice discharge through a confluence. If the dimensional analysis is carried out using $b_{c^{\prime}} Q_{1}+Q_{2}$ $\left(=Q_{c}\right)$, and $\rho$ as the repeating variables, the following functional relationship emerges for the limiting condition of a contiguous layer of accumulated ice discharging through a confluence:

$$
\begin{gathered}
\eta=\varphi_{\mathrm{L}}\left(\frac{Q_{1}}{Q_{1}+Q_{2}}, \frac{b_{1}}{b_{\mathrm{c}}}, \frac{b_{2}}{b_{\mathrm{c}}},\left(\frac{Y}{b_{\mathrm{c}}}\right)_{1,2, \mathrm{c}}, \frac{k_{\mathrm{b}}}{b_{\mathrm{c}}}, \frac{k_{\mathrm{i}}}{b_{\mathrm{c}}},\right. \\
\left.\eta_{1}, \eta_{2}, \frac{H_{1}}{b_{\mathrm{c}}}, \frac{H_{2}}{b_{\mathrm{c}}}, p, \frac{\rho_{\mathrm{i}}}{\rho}, \phi, \mu, \alpha, \beta\right) .
\end{gathered}
$$

An awkward aspect of the foregoing dimensional analysis is the precise definition of incipient jamming. The analysis assumes that incipient jamming happens when the water and ice inflows to a confluence begin to exceed outflows of water and ice. Actually, there probably are shades or degrees of incipient jamming; outflows of water and ice may be less than inflows and yet a jam may not have formed. Jam formation may be attended by unsteady, interactive processes in which water and ice flows adjust in accordance with, for example, changes in ice concentration and layer thickness. The foregoing analysis, though simplifying the actual processes, nonetheless leads to useful sets of nondimensional parameters for describing the general characteristics of ice movement through confluences.

\section{DISCUSSION}

Having identified categories for classifying different situations of ice discharge through confluences and having established sets of nondimensional parameters for discussing, in general terms, ice discharge through confluences, it is interesting to evaluate which categories actually seem to be the most problematic. The categories indicating a higher incidence of problems should be given a higher priority for further investiga- 
tion. Other categories may be fairly rare.

A partial evaluation can be obtained from Tuthill and Mamone's (1997) report, which lists about 44 sites known to have ice jam problems. Eight sites were selected as being potentially amenable to a structural solution to mitigate jamming. Of the 44 confluence sites, 15 involve rivers entering a lake or reservoir (e.g., Aroostook River entering Tinker Dam Reservoir). Of the remaining river channel confluence sites, several have one channel merging with a channel subject to a significant backwater condition. Examples include the Yellowstone River confluent with the Missouri River upstream of Lake Sakakawea, and the Salmon River merging with the Connecticut River at a reach subject to tidal slowing of river flow. Of the eight sites selected for potential structural measures, six have a river entering a lake or a reach of flow slowed by a backwater condition. These sites coincide with categories I.3, I.4, II.3, or II.4 (Table 1), where one confluent channel has sluggish or negligible flow velocities or is covered by stationary ice. The seventh and eighth sites selected do not have sluggish flows at the confluence. One site is a lake entering a river, which is not so much a confluence as an extreme constriction. The other site is the confluence of the Missouri and Mississippi rivers. The ice discharge situation for that site appears to be category I.1; ice drifts from the Missouri into the Mississippi, which releases a negligible amount of ice during jamming events at the confluence. Initial assessments of ice transport through the MississippiMissouri confluence indicate that local bathymetric irregularities at the confluence play an important role in jamming at the site.

Detailed information on the causes of ice jamming at the confluence of two channels is not provided in the report by Tuthill and Mamone (1997), which focuses mainly on the aforementioned eight confluences. Nonetheless, it is possible to hypothesize that a major proportion of jam problems at confluences occur for the following two reasons:

- Ice from one channel discharges into a channel that has a sluggish flow (a lake is a limiting example of this situation) or has a stationary ice cover that initiates jamming.

- Bathymetric irregularities in confluence geometry retard ice discharge and initiate jams.

It is possible to hypothesize further that it is not common to find ice jam situations caused by the merging of ice discharged from two confluent channels. The joint probability of ice discharging simultaneously from two channels into a confluence is likely to be relatively small; therefore, the frequency of these jamming situations is likely to be small. Somewhat of an exception is ice discharge through confluent branches of a braided-meandering channel or a river channel that initially bifurcates around an island (e.g., the Upper Niagara River splitting then merging around Grand Island) or a large bar. Jamming of confluent ice discharges may be more likely during freezeup, when channels in an entire watershed form and convey ice, rather than at breakup, which arguably is more haphazard because of the greater diversity of factors affecting it.

The hypotheses mentioned above, which form a portion of the findings of this study, point further investigations toward the following two specific objectives:

- Determine the conditions needed for two confluent ice discharges to jam. Attaining this objective entails doing parametric experiments to evaluate the jamming limits of the more important parameters identified in eq 7 and 12.

- Determine the processes whereby ice (from one or two channels) moves through a confluence, and assess how confluence bathymetry may substantially hamper ice discharge through confluences. This objective is addressed through a hydraulic model described later in this report.

\section{PARTICLE IMAGE VELOCIMETRY}

At the limiting condition of maximum ice discharge through a confluence, ice movement is at a state of incipient jamming. Ice slows and is on the verge of accumulating and constricting water flow. Beyond this condition, ice accumulates, jams, and constricts flow. To monitor and map incipient jamming in a flow field as potentially complex as a confluence, it is useful to use instrumentation that maps whole fields of ice and water velocities. One such form of instrumentation is particle image velocimetry (PIV). Its use for mapping ice velocities was examined here.

\section{Background}

The key components of PIV are a series of images showing displacements, a personal computer with a frame-grabber, and software for processing the images. The technique has developed rapidly in the past few years, making use of 


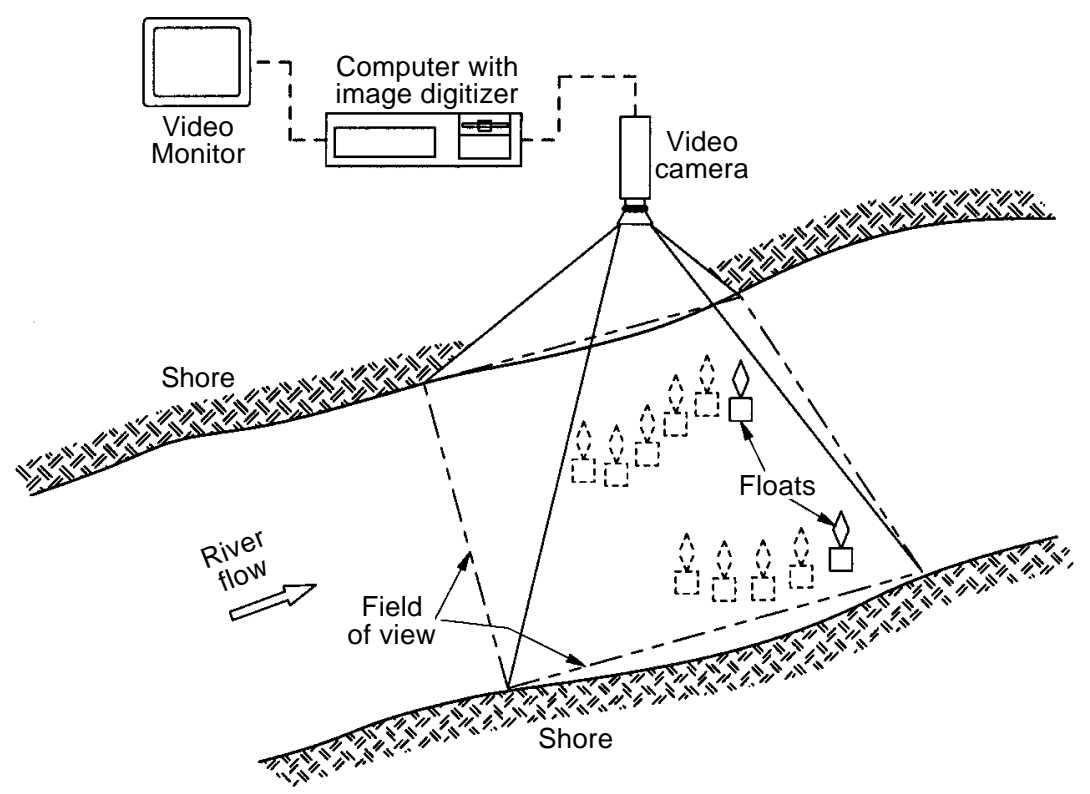

Figure 5. Typical setup used in an early PTV system for tracking individual floats on water surface.

recent hardware and software developments, to the extent that it now is practicable for determining and mapping fields of ice movement.

Imaged-based techniques for measurement of particle and fluid motion have been used for about two decades to determine two-dimensional distributions of flow velocity in laboratory experiments and models. During the past decade, the techniques have evolved along essentially two lines: particle tracking velocimetry (PTV) and PIV. The two techniques differ in the image-processing principle used for determining velocities.

The origin of PTV stems back to various flowvisualization techniques (Adrian 1991). It requires low concentrations of seeding particles, each particle being tracked individually in successive images containing short streaks or tracks that, for a known period, can be interpreted to give velocities. The progenitor versions of PIV were of the PTV type, because of limitations in data-processing capacity of computers. Murthy (1991), for example, describes the use of a rudimentary PTV technique for obtaining distributions of flow velocity in hydraulic models of lock and dam facilities. Figure 5 illustrates the typical setup of the system used. A video camera and computer with image digitizing software are used to track the movement of single floats, appropriately ballasted to give either surface or depth-averaged velocities. This technique, though still useful for tracking the trajectory and velocities of a few, iso- lated drifting ice masses, is rather tedious for determining velocity vectors for numerous ice pieces, as in a rubble-ice field. Also, it cannot be used for measuring subsurface patterns of flow and particulate transport.

PIV has its origin in a technique known as laser speckle velocimetry (LSV), which was developed as a technique for determining strain fields in deforming solids. Coherent light (i.e., laser light) scattered from a solid surface creates a speckle pattern, which changes as the solid deforms. Whereas particle tracks usually can be interpreted from superimposed images by eye, changes in speckle patterns are virtually impossible to unravel that way. With the development of the Young's fringe method (a laser beam illuminates a double-exposed specklegram to produce a Young's fringe pattern that reveals information on the displacements of points on a surface), it became possible to ascertain the movement and, thereby, velocities of a field of points. The next step, taken in the late 1970s, was to use LSV procedures for measuring fluid motion in various flow situations. This step required seeding a flow with lightscattering particles, fine enough to move exactly with the fluid. Practical limitations on the amount of seed particles (tracers) for use in fluid experiments led to the recognition (Adrian 1984, Pickering and Halliwell 1984) that LSV imaging of fluid flow, strictly speaking, was not LSV; rather, it was a separate mode of image velocimetry that 
became PIV. PIV is distinguished from LSV and PTV in the concentration of seed particles it requires (a much greater concentration is needed for LSV, but far less for PTV) and, relatedly, in the method used to interpret or interrogate (the technical term used for this purpose) images.

Recent developments in instrumentation, together with computer hardware and software, have made PIV practicable for obtaining accurate, detailed measurements of instantaneous and averaged velocity fields for diverse situations of flow and fluid-transport processes. The technique is also capable of yielding distributions of flow and particle velocities at sections across flows and determining time-histories of velocities at points within flows. With appropriate particle seeding, PIV also can be used to obtain data on variations in density and temperature within flows. The interested reader might refer to Adrian (1991) for a thorough review of the development of PIV.

This very brief history of PIV glosses over its many intricate aspects, but it emphasizes an important point, namely, that PIV is essentially a pattern-recognition procedure. Changes in seedparticle position create Young's fringe patterns that can be interpreted to yield velocities in so-called interrogation spots, or subareas, of flow fields. The interrogation methods currently in use are primarily statistical. They infer the proper pairings of particles and measure the average displacement of particles in or between interrogation spots. This process entails either auto- or cross-correlation analysis to establish the most probable magnitude and direction of particle displacements within the interrogation spot. The correlation algorithm used for the present application is illustrated and explained in Figure 6.

Within an interrogation area, an interrogation

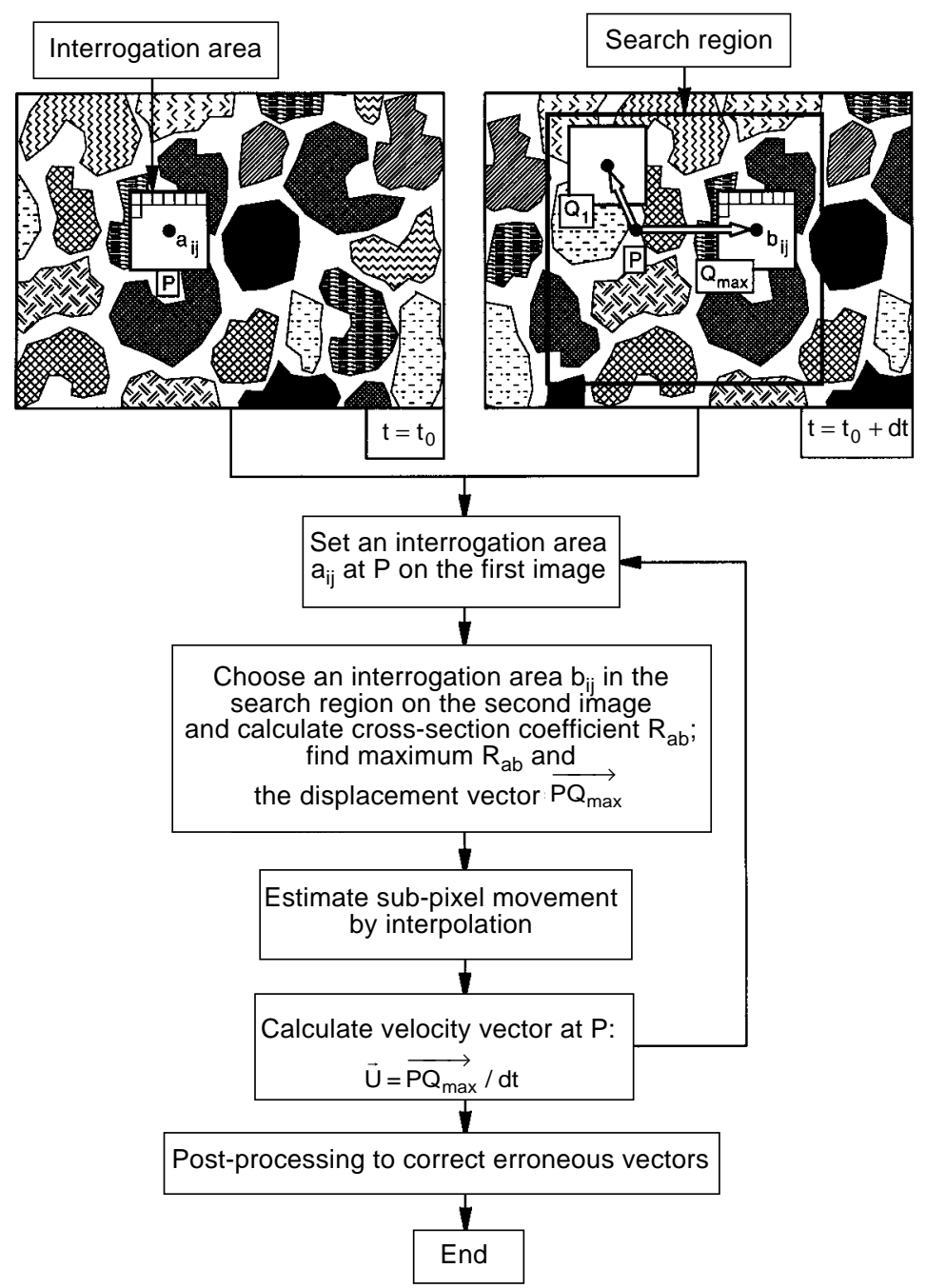

Figure 6. Correlation algorithm used for determining ice velocities. 
spot $a_{\mathrm{ij}}$ is selected at point $P$ on a gray-level image at time $t_{0}$. A second spot $b_{\mathrm{ij}}$ is located away from point $P$ on a subsequent image taken at time $t=t_{0}$ $+d t$. A cross-correlation analysis is conducted to find the maximum value of cross-correlation coefficient $R_{\mathrm{ab}}$. Estimation of sub-pixel movement yields the most probable displacement of $a_{\mathrm{ij}}$ during the period between the images. Once the displacement is known, a velocity vector is determined. Assembly of velocity information from interrogation spots enables a composite flow field to be formed.

During recent years, PIV has been used as a conveniently fast method for mapping relatively small-scale velocity fields, or subareas of flow fields, in a variety of small-scale experimental flow facilities. It has mainly been used for determining flow distributions in small areas (nominally $20 \times$ $20 \mathrm{~mm}$ ). Extension of PIV for larger flow fields poses problems with flow-seeding and illumination. Recently, however, Fujita and Komura (1994) and Aya et al. (1995) demonstrated that PIV is adaptable to determine distributions of surface velocities for flow in a river channel. Surface-flow patterns in most river sites are sufficiently large in dimension and low in frequency as to be amenable to PIV applied in a scaled-up format not requiring the high concentrations of seed or tracer particles needed when PIV is used to determine intricate flow structures at laboratory scale. Using video images from a camera sited on a tower overlooking the river, Fujita and Komura (1994) and Aya et al. (1995) found that drifting debris (small pieces of wood, weeds, etc.) and foam (from naturally occurring humic acids in rivers and lakes) on water surfaces served as tracers, enabling PIV interpretation to obtain velocity vectors. Their successful adaptation of PIV for determining velocities of surface currents and drifting debris prompted the present consideration of PIV for determining ice velocities.

The main problems that must be faced in applying the technique to larger areas of flow, as usually required for hydraulic models of river sites and for field application, are the amount and uniformity of particle seeding and adequate lighting needed to create a useable set of gray-level images. Mapping of a flow field requires an adequately large amount of seeding material to ensure that, at any instant, each interrogation spot in the flow field contains at least one particle. Reasonably constant illumination is needed to ensure stationarity of the conditions under which video images are interrogated. Application of PIV for determining vector fields of water-surface velocities and ice velocities requires the same overall procedure as used for measuring various laboratory flows, except for two factors. It does not require a laser beam or sheet, and it is applied over a much greater area than is typical of prior laboratory use of PIV. The technique uses an interrogation algorithm developed by Fujita and Komura (1994) and extended by Aya et al. (1995). They showed that, for larger scale flow fields-typical of the surficial flow distributions in rivers conveying floating debris or ice-debris and foam at areal concentrations common in rivers were adequate tracers for application of PIV. They also showed that natural lighting can be adequate for obtaining video images of suitable quality over the period needed to determine the velocities.

The extension of PIV to ice movement raises several questions about the limits of the PIV technique for determining ice velocities: Is the technique suitable for all sizes of ice pieces? Can it handle mixtures of ice-piece sizes? What areal concentrations of ice are required? Are there ice speed limitations? What frequencies of velocity fluctuation can be analyzed using PIV? In many respects, the collective answer to most of these questions is that the field of view contained by an image, and the period between images, must be commensurate with the requirements for statistical analysis of the interrogation spots. Ice piece size is not an issue, provided the ice piece is clearly discernible in a video, photograph, or radar image. Mixtures of ice piece sizes also are not an issue, because the image-processing method can be modified to suit particle densities. The technique is suitable for all areal concentrations of ice. However, if ice is used as a seed tracer for determining flow patterns, then ice concentration must be such that, at any instant, each interrogation spot contains at least one ice piece. The issue of ice-speed limitation is best addressed in terms of the period between images analyzed. Faster ice pieces require shorter intervals between images, especially if the ice piece trajectory is changing.

The PIV technique described here uses and extends the PIV technique as adapted by Fujita and Komura (1994) and Aya et al. (1995) for determining velocities of objects moving on water surfaces. It was used to obtain whole-field velocities of water and model-ice movement in a hydraulic model simulation of the confluence of the Mississippi and Missouri rivers. PIV had not been used before to determine velocities in an experimental setup of the magnitude used in the present study, 
though its field application by Fujita and Komura (1994) and Aya et al. (1995) suggested that the present application was feasible.

\section{Field use of PIV}

Besides its use for the model study described here, PIV holds good promise for application with remote-sensing methods for monitoring ice in various field situations. At present, such methods are used extensively to determine the presence of ice, its general pattern of movement, and the trajectories of individual ice masses. PIV, in appropriate conjunction with remote-sensing methods capable of producing sequences of images of moving ice, would enable whole-field velocities of ice and possibly water to be determined. The two primary requirements for applying the PIV technique are adequate images of moving ice and a set of at least four markers of known coordinates in the field of view. The images could be a direct video record of the ice movement through the location, a set of photographs taken at a close interval of time, or they could be of a series of images generated from a radar.

Aerial photographs and videos are already used extensively for monitoring ice, identifying obstructions to its movement, and assessing damage caused by it. Ashton (1986) describes their use for monitoring ice conditions on rivers and lakes. In recent years, videos of ice movement have been used to obtain more than a visual record of ice and ice runs in rivers. Dobrowolski et al. (1992), for instance, describe the use of video recording and computer software to determine concentrations of frazil slush moving in the Vistula River, Poland. If taken at an elevation commensurate with the requisite areal concentration of ice pieces, and for a known aircraft speed, not much effort is needed to produce areal images that could be analyzed using the PIV technique described herein.

As an alternate form of video image, radar images converted to video images could be analyzed using the PIV technique. Figure 7, for instance, shows a marine radar image of ice moving through the fairly complex bathymetry of the Grass Island Pool reach of the Upper Niagara River. The reach geometry is also shown in Figure 7. Once the dimensions have been established, velocity vectors of moving ice could be interpreted from such video images. However, in the case of Figure 7, the period between the radar images was 10 minutes, which is too long to meaningfully map velocity vectors for the ice pieces that were mov- ing through the field of view. Radar images at about 1 minute would have been suitable for PIV analysis.

\section{MODELING ICE DISCHARGE AND JAMMING PROCESSES IN CONFLUENCES}

To investigate the processes whereby ice discharges through, or jams, in river confluences, a general hydraulic model was built to accommodate a two-channel confluence of variable geometry. This section describes the model, the versatile instrumentation system used to obtain whole-field mappings of water and ice velocities in the hydraulic model, and how measurements were made during an investigation of ice discharge through the confluence of the Missouri and Mississippi rivers.

\section{Ice movement through the confluence of the Mississippi and Missouri rivers}

The confluence of the Mississippi and Missouri rivers is prone to ice jams that are infrequent, but damaging and expensive when they do happen. The conditions at the confluence when jams form typically include almost equal, and low, water discharges in both rivers. Jamming at the confluence causes some flooding and damage to shoreline structures, but the main difficulty is obstruction to tow-barge traffic on the river, which cannot get through the jams.

The overall orientation and geometry of the confluence is depicted in Figure 8, which also presents the layout of the general hydraulic model. Figure 9 illustrates ice moving through the confluence in January 1994. This case study is an example of a confluence problem attributable mainly to local bathymetry, and possibly wind, rather than to difficulties in merging ice discharging from two confluent channels.

Discussions with engineers from the U.S. Army Engineer District, St. Louis, provided the following information about the difficulties with ice discharge through the confluence:

- Difficulties typically occur when flows in the Mississippi and Missouri rivers are low (nominally $50,000 \mathrm{ft}^{3} / \mathrm{s}\left[1415 \mathrm{~m}^{3} / \mathrm{s}\right]$ or less in each channel).

- In recent times, navigation through the confluence was shut down in 1977, 1979, 1989, 1990, and 1994.

- Ice predominantly comes from the Missouri River. The Mississippi River usually has a 


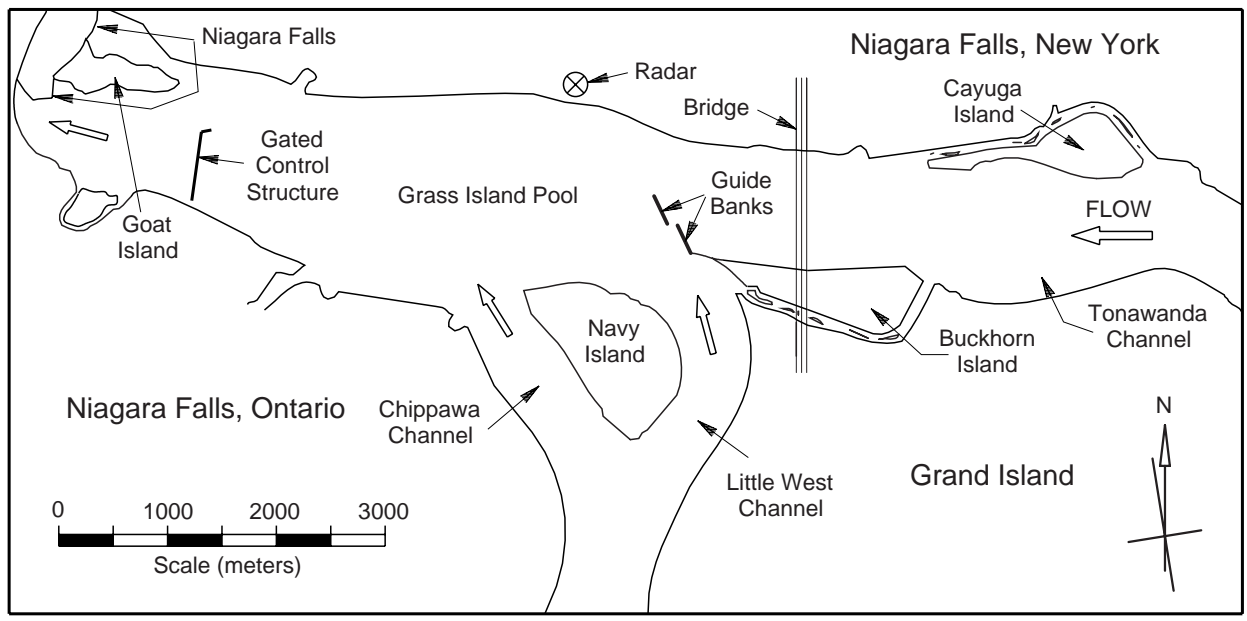

a. Layout of the pool.

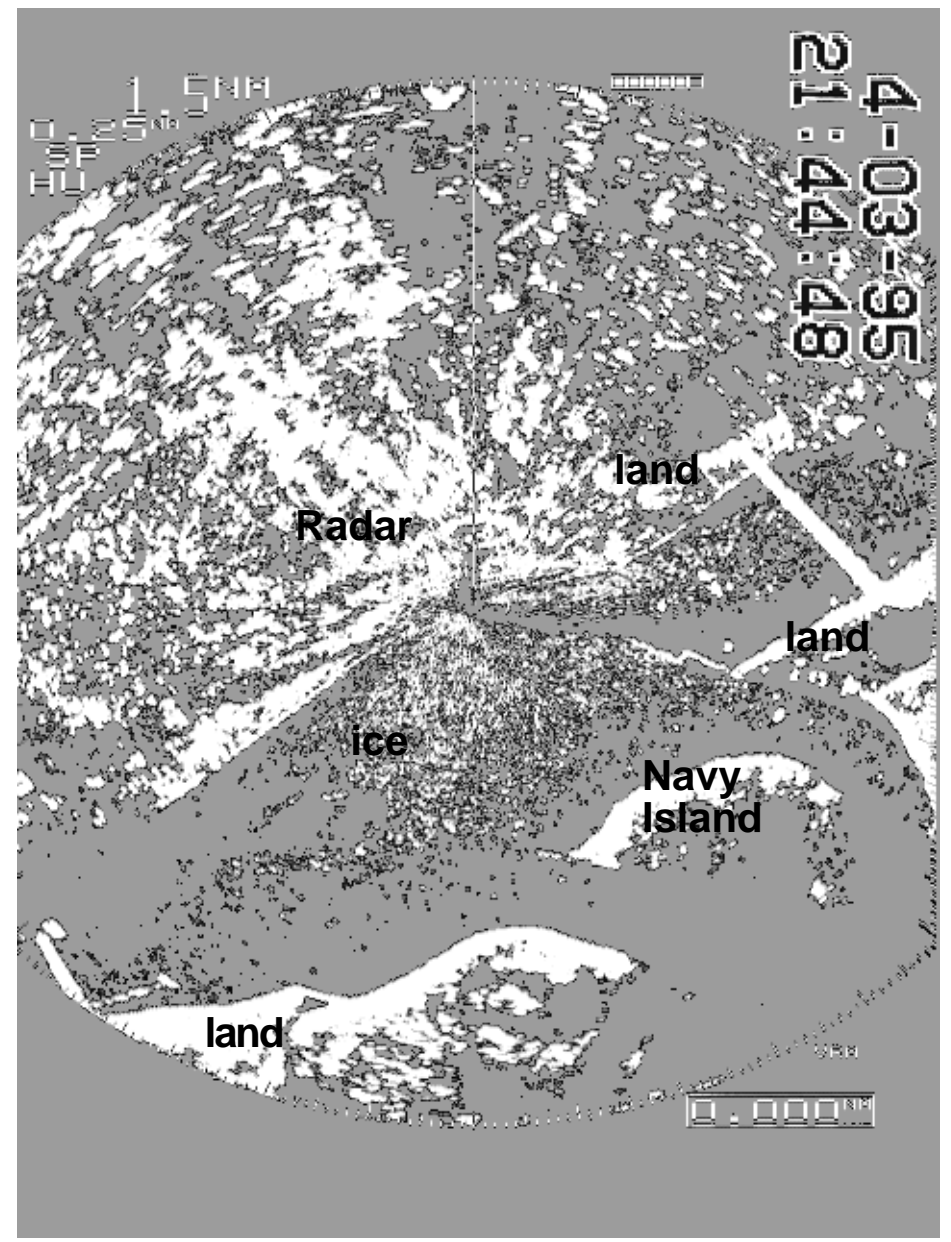

b. Marine radar image of ice movement through the pool.

Figure 7. Ice movement through a channel confluence at the Grass Island Pool of the upper Niagara River. 


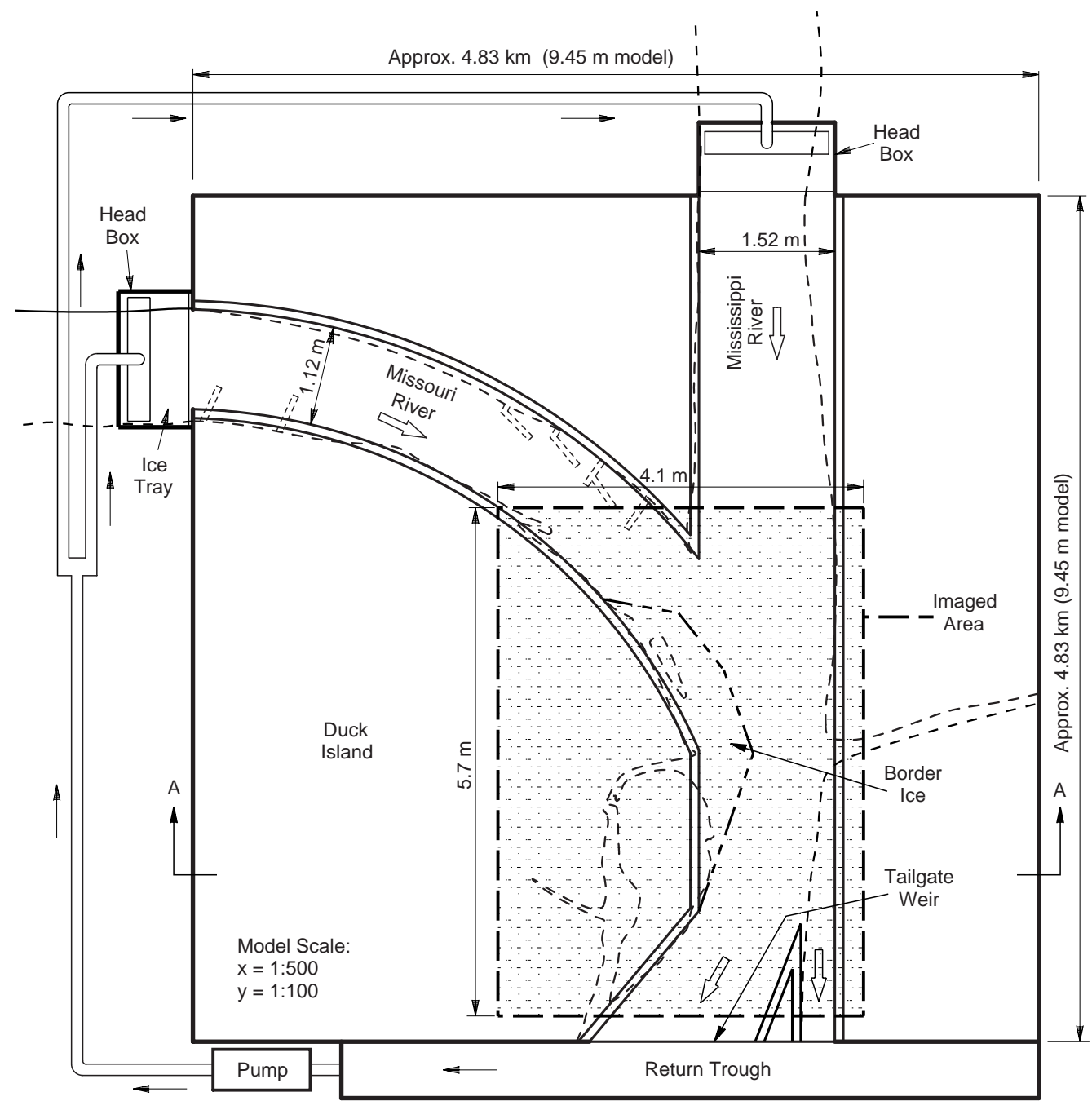

PLAN VIEW OF MODEL BASIN

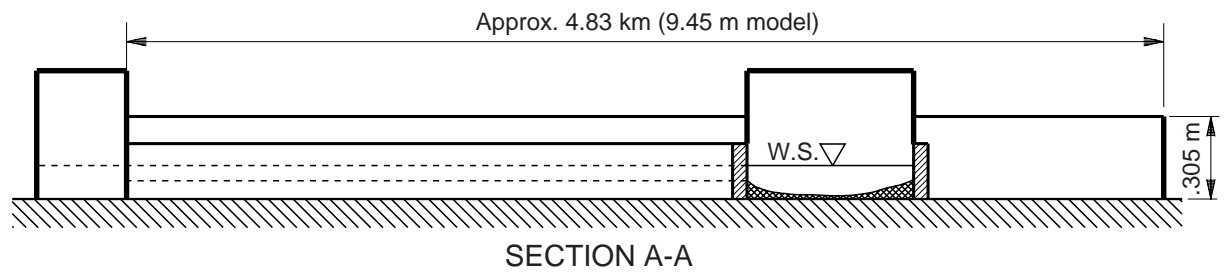

Figure 8. Layout of the general hydraulic model showing the model confluence of the Mississippi and Missouri rivers. 


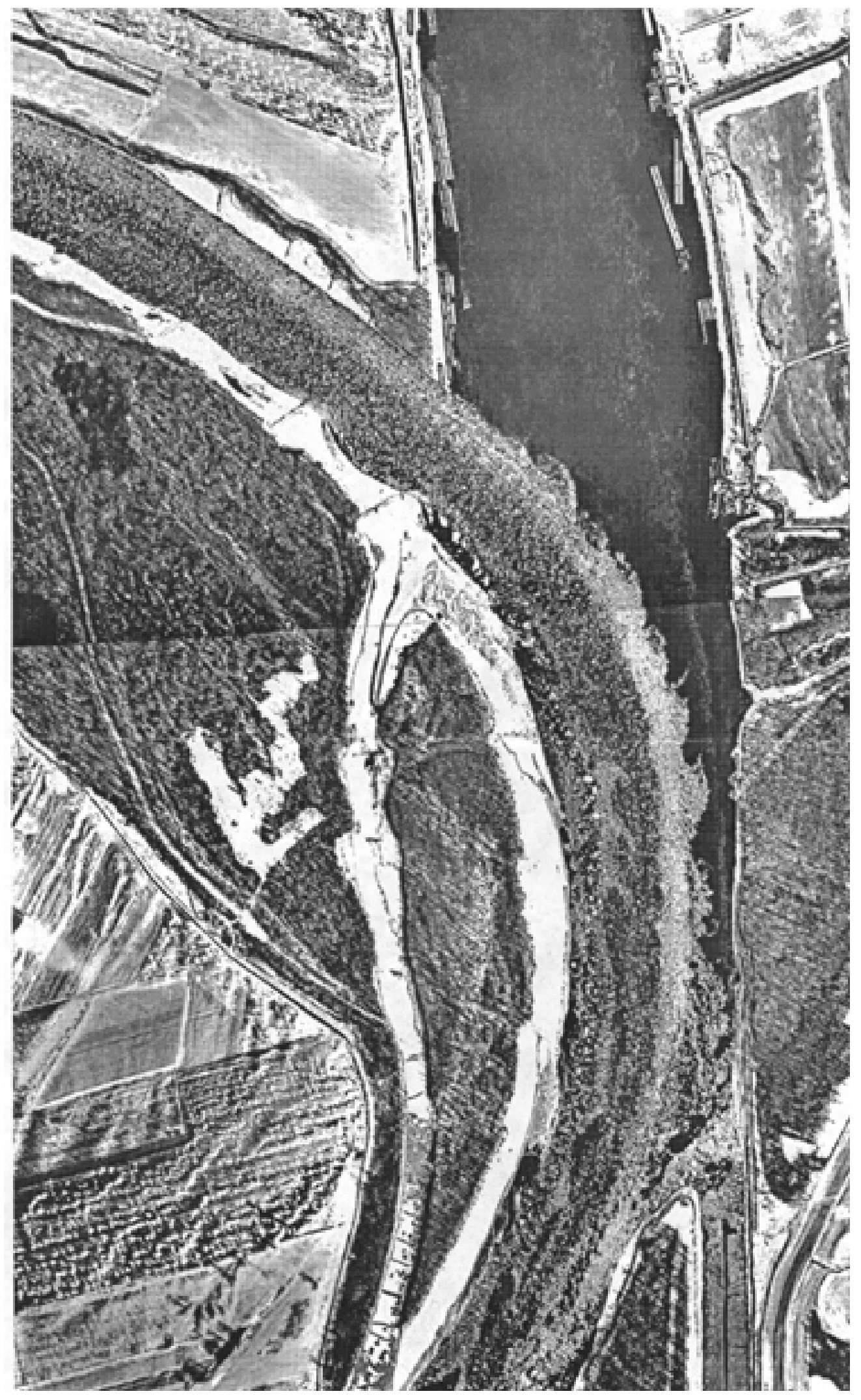

Figure 9. Ice movement through the confluence of the Mississippi and Missouri rivers, 19 January 1994. 
more or less stable ice cover, and its ice, by and large, seems to be retained at the several lock and dam facilities upstream of the confluence.

- The main difficulty produced by ice moving through the confluence is blockage of towbarge traffic up and down the Mississippi on its way to and from the Illinois River. Tows have great difficulty moving through the ice because of lateral pressures exerted through the ice. Those pressures tend to pinch the tows and close tow tracks opened through the ice. Also, some docking facilities along the Mississippi River's bank at the confluence have been damaged by ice.

- The Corps engineers were pondering the following actions to address difficulties in ice movement through the confluence-removing the point bar along the inner side of the confluence, realigning the confluence, and blocking leakage of flow along a small slough behind the point bar. The point bar and small slough are evident in Figure 9.

\section{Hydraulic model configuration}

The model comprises a large plywood tray, 9.5 by $9.5 \mathrm{~m}$ in plan dimensions (Fig. 8). The tray may contain model confluences simulating a range of confluence geometries besides that of the Mississippi and Missouri rivers. Channel widths $b$ and alignments $\alpha$ and $\beta$ can be readily altered. Flow is recirculated by means of a pump, whose discharge splits in two lines to the headbox of each channel. An overflow tailgate at the downstream end of the model is used to regulate water levels in the model (see Fig. 10).

The model simulated a 4830- by 4830-m area of the confluence at horizontal and vertical length scales of 1:500 and 1:100, respectively.

Three bathymetries of the confluent channels were simulated for the tests:

- Rectangular channel cross sections.

- Alluvial-bed bathymetry approximately that of the Mississippi-Missouri confluence.

- Alluvial-bed bathymetry with border ice approximately simulating the "accumulation" condition depicted in Figure 9 for the confluence.

These represent an ascending order of bathymetric complexity that has helped determine the effects of channel bathymetry on ice movement through the confluence. The rectangular channel section is the basic case of two confluent rectangular channels and the simplest configuration for numerical simulation. The addition of alluvial bed

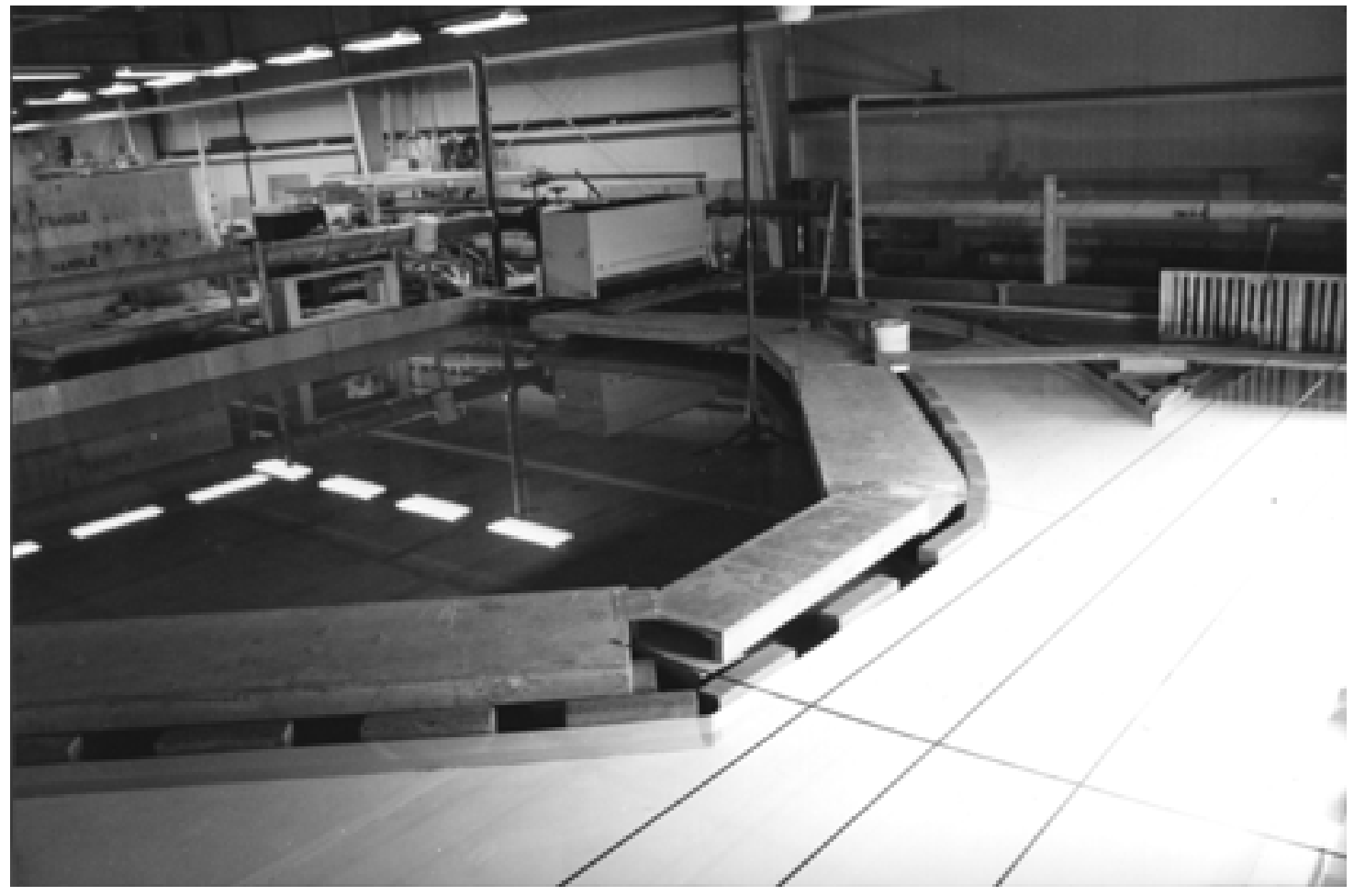

Figure 10. View of the hydraulic model's alluvial bed bathymetry. 
bathymetry makes the model more representative of the Mississippi-Missouri confluence. The bathymetry used for the model did not include, however, a large dune, which presumably formed during the 1993 flood at the outflow of the Missouri. Details on the dune were not available at the time of testing. The addition of border ice, formed over a large point bar along the west bank of the confluence, allows the model (in plan at least) to more closely replicate the confluence condition illustrated in Figure 9.

The alluvial bed bathymetry between the sheet metal walls was replicated using a bed of coarse sand (1.2 $\mathrm{mm}$ average diameter) adjusted to simulate the channel bathymetry data from a 1972 navi- gation chart. The surface of the bed was fixed using cement, and was painted white to facilitate use of the PIV method (Fig. 10). Border ice was replicated using strips of sheet metal bent and placed to block off the channel to simulate the formation shown in Figure 8.

Ice drifting from the Missouri River was simulated using 3-mm-diameter polyethylene beads, which have a specific gravity of 0.90 , slightly less than that of freshwater ice (0.92). For a horizontal scale of 1:500, the beads approximately replicated 1.5-m-diameter pans of ice in the Missouri River. The beads, which are black, are readily visible against the white channel bed, and were fed into the model Missouri River at a controllable rate

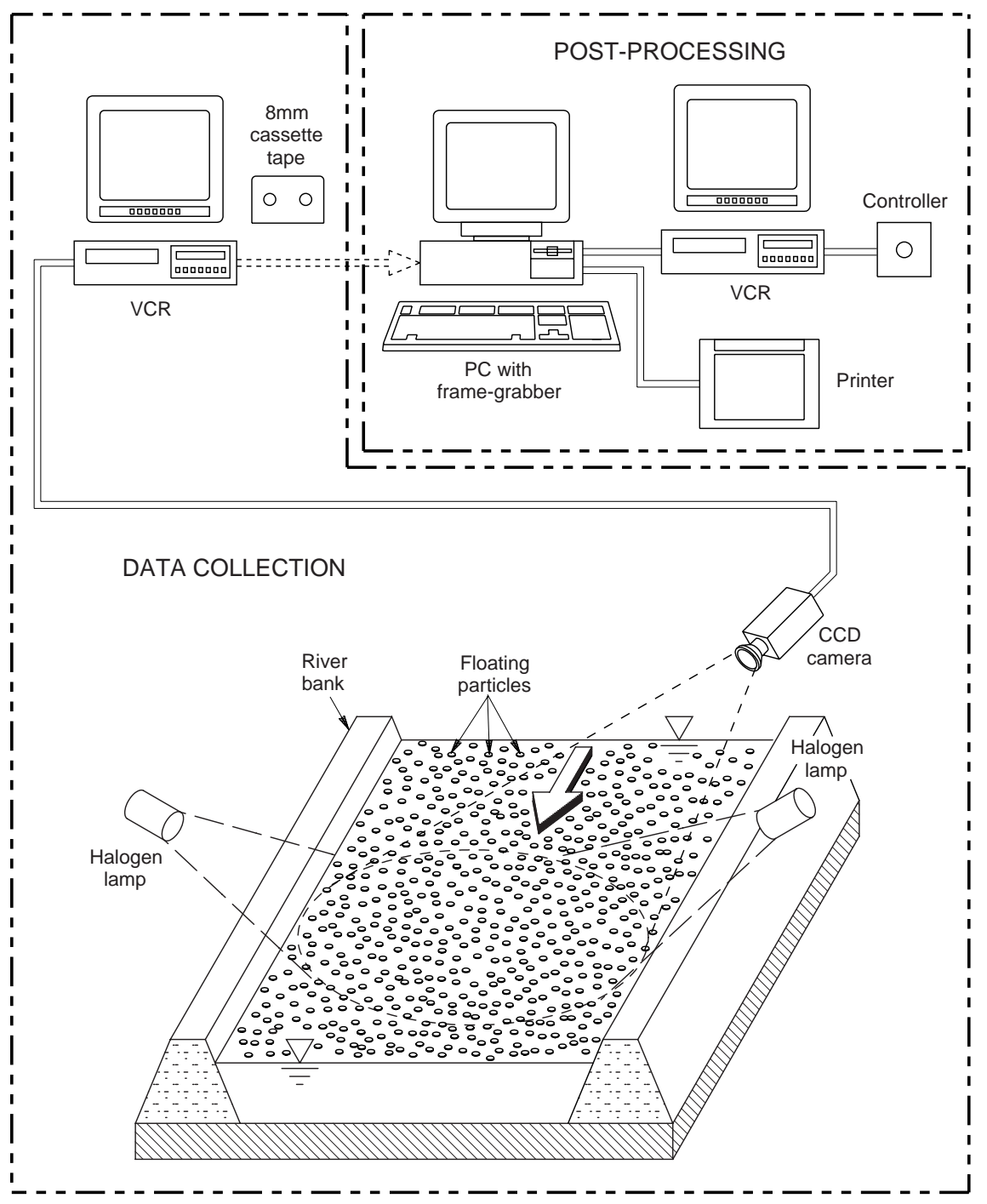

Figure 11. Setup of the PIV system used in this study. 
from a hopper with a revolving conveyor belt at its base. The rate of bead discharge into the model was regulated by means of a sliding gate at the edge of the belt.

\section{PIV system for measuring water and ice velocities}

The layout of the PIV system used for the model is given in Figure 11. A color CCD camera (Sony SSC-C374) with a wide-angle lens, having an 8$\mathrm{mm}$-focal length, is used to capture the images. The camera is mounted $5.4 \mathrm{~m}$ above the model, at an oblique angle such that a 5.7-by 4.1-m area forms the camera's field of view. The area is delineated in Figure 8. Sixteen 500-W halogen lamps uniformly illuminate the area. Reflections are eliminated through careful positioning of the lights.

Video images were recorded using a Sony EVO9650 video recorder. They were subsequently digitized by means of a frame-grabber (Matrox Meteor RGB). The digitized images (i.e., video frames) were composed of 640 by 480 pixels having 8-bit gray-level resolution. A $133-\mathrm{MHz}$ Pentium personal computer was used to process and store digitized video images. Custom software was written in the $C$ language to control the VCR and the frame-grabber during playback and frame grabbing. The subsequent image processing software, essentially a cross-correlation algorithm including software to correct the areal distortion of the video image, was written in Fortran 77. A standard color monitor was used for on-line display of the video imaging.

Particles with the same specific weight, but different color and shape, were used as flow tracers for the open-water and ice-covered flows. Low concentrations of polypropylene beads (spaced several beads per $100 \mathrm{~mm}^{2}$ ) released onto the water surface were used as tracers for mapping the open-water flows. For the ice-covered flows, in which a more or less continuous layer of black beads moved through the confluence, ice vectors were determined using a low concentration mixture of square plates $(10,10$, and $1 \mathrm{~mm})$ of white polypropylene and the black beads. The plates were needed to ensure that adequate patterns were formed in the layer of moving model ice. The size of both tracer particles, the beads and the squares, were sufficiently small that they followed the movement of water and ice. Importantly, they also were large enough to meet the size constraint (i.e., to occupy at least one pixel of the video image) needed for adequate image resolution.

\section{Test procedure}

Water flow through the model was set in approximate accordance with the conditions depicted in Figure 9 (19 January 1994), such that the Mississippi and Missouri rivers conveyed 48,400 and $60,600 \mathrm{ft}^{3} / \mathrm{s}\left(1370\right.$ and $\left.1715 \mathrm{~m}^{3} / \mathrm{s}\right)$, respectively. Water levels were adjusted by means of a tailgate at the downstream end of the model. The ice hopper was set in motion, releasing beads onto the Missouri River in a single-thickness layer. Most tests were run with the beads discharged at maximum areal concentration. Some runs, though, were made with lesser concentrations to qualitatively determine how ice concentration affected ice movement through the confluence. Dye visualization was also used to establish the principal water velocity distributions.

Once the PIV system was set up, model ice pieces (plastic beads) at a low areal concentration were released into the modeled flow to determine and map the water velocity field in the confluence. Subsequently, model ice was discharged into the modeled Missouri River channel at a set rate. Model ice velocities were measured using white plates placed among the black beads.

\section{Image recording and processing}

Prior to videotaping of water flow and ice movement, two aspects of the PIV system had to be calibrated: the dimensions of the field of view, and the PIV-measured velocities. A start-up segment of video was made to correct the image distortion introduced by the video camera's lens and angle of view. The start-up segment entailed videotaping distance markers and a grid of known spacing over the area of interest. The markers were placed at locations whose coordinates were known relative to the position of the video camera. The start-up video images allowed corrections to be made for areal distortions resulting from the video camera's oblique view of the model.

The second calibration task required checking the accuracies of the water and ice velocities obtained using the PIV system. This was completed by comparing PIV velocities with those measured by timing hand-released tracers as they traveled known distances in the model. As the dimensions of the area of interest and the period between images are set earlier, velocities follow directly.

Before model ice was discharged into the model, video images were taken of the open-water flow conditions to determine the open-water flow field. 


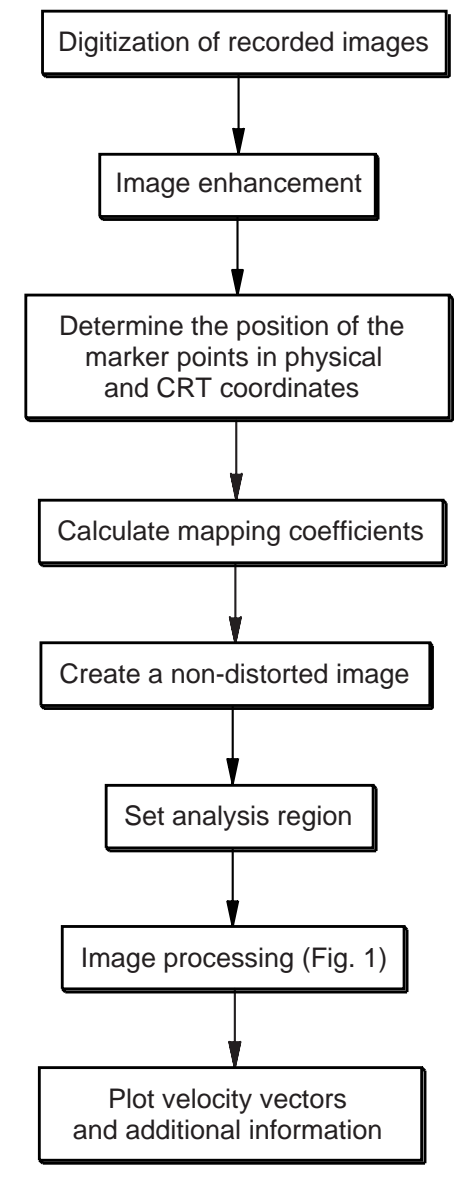

Figure 12. Flow chart of principal steps in the PIV technique used in this study.

As mentioned above, beads at low concentration were scattered over the free surface of the flow. Subsequently, model ice was discharged from the hopper and allowed to drift into and through the confluence in a bank-to-bank, closely packed single layer. The recording time and region to be analyzed were established in accordance with the objectives of the investigation. For the present study, the recording continued for about $10 \mathrm{~min}$ utes during each flow condition and covered the 5.7- by 4.1-m area of the modeled confluence.

The image-processing steps followed were essentially those described by Fujita and Komura (1995), who adapted the method for use in mapping water-surface velocities of rivers. Their method was modified here for determining the model-ice velocity field (Fig. 12).

The first step in image processing required determining the mapping coefficients to relate the actual coordinates of the model area to those projected on the cathode ray tube (CRT) forming the computer screen. The coefficients correct the opti- cal distortion resulting from the video camera's field of view. The correction method detailed by Fujita and Komura (1994) was used for this purpose. The distorted and corrected images are shown in Figure 13. For these experiments, the pixel size was specified as 8 by $8 \mathrm{~mm}$, resulting in a corrected image containing 706 by 518 pixels.

The next step was to delineate the boundaries separating out the analysis region (area of flow) within the corrected image plane where the PIV analysis was performed. Regions outside of this area are then blanked out. The PIV analysis was applied only in interrogation spots that were at least $50 \%$ within the analysis region, so that velocity vectors could be determined at loci near the boundaries.

The cross-correlation algorithm described previously was used to determine interrogation spot movement between two video frames sampled 1 second apart. For the fairly slow-moving model ice pieces, this period practically gave an "instantaneous" velocity vector field, with the slowest particle moving at least one pixel on the CRT screen. The interrogation spot size was 31 by 31 pixels, while the interrogation area was chosen such that velocity vectors varied from 2 to 16 $\mathrm{cm} / \mathrm{s}$ in the main flow direction and from 1.5 to $15 \mathrm{~cm} / \mathrm{s}$ in the direction normal to flow. The velocity vectors were computed for a grid of 15 pixels in the main flow direction and 10 pixels in the normal-to-flow direction. Time-averaged values of water and ice velocities were determined from 100 instantaneous vector fields.

Once the processing was made final, crosssectional velocity profiles for any section of the model were readily plotted. For the case of icecovered flow, the boundary between areas covered and areas free of ice was detected using the degree of gray level of the background. Approximately 100 seconds were needed, using the 133$\mathrm{Hz}$ Pentium computer, to produce the 960-vector velocity fields presented as Figure 14 . This period translates loosely to an approximate rate of 0.1 second per vector in the flow field. With further improvements in the technique (hardware and software), the processing time will decrease.

\section{RESULTS}

The results given here illustrate major features of water flow and ice movement through the confluence of the Mississippi and Missouri rivers. Presented first are mappings of water velocity distribution in the model confluence for the three 


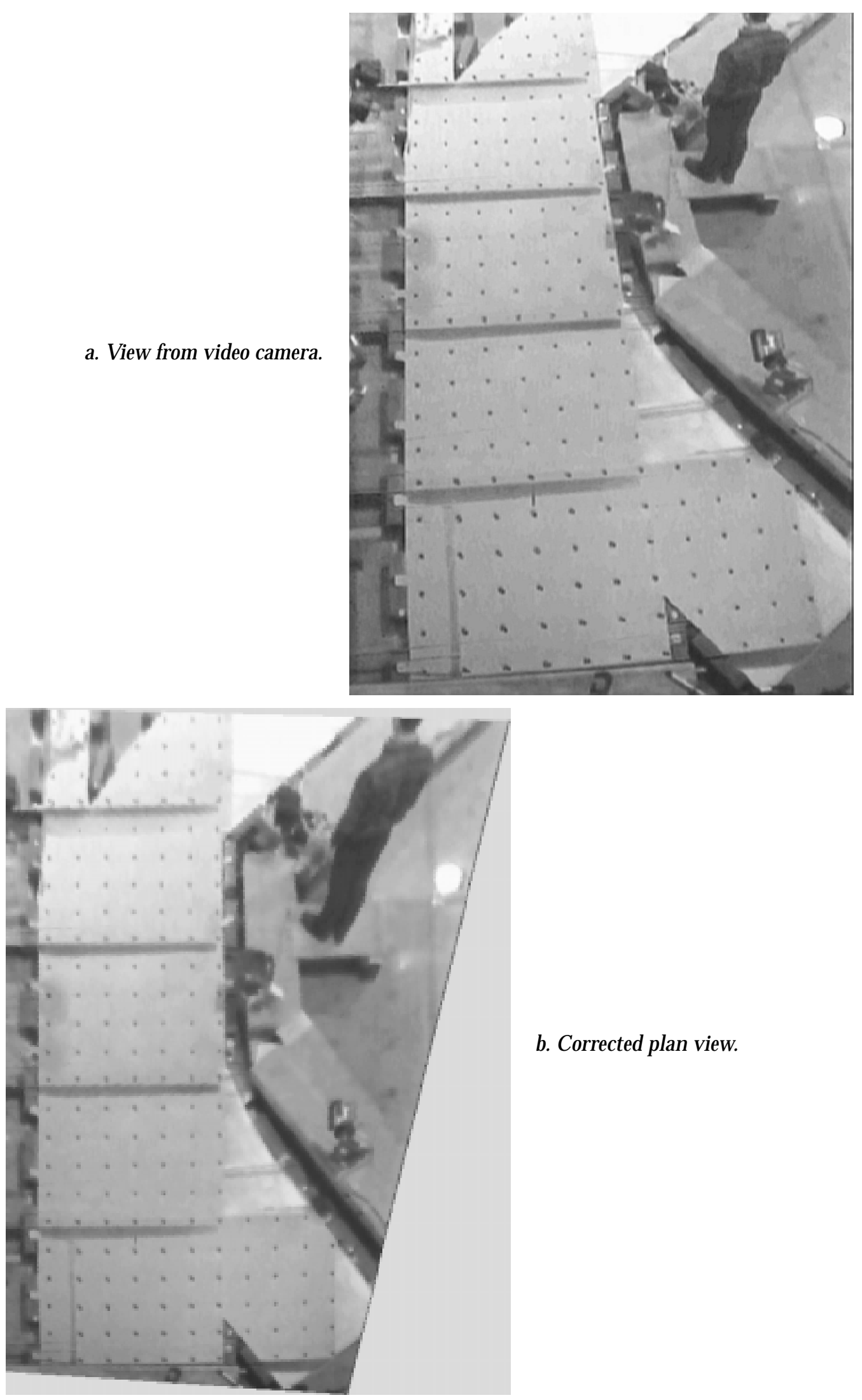

Figure 13. Correction of the field of view. 

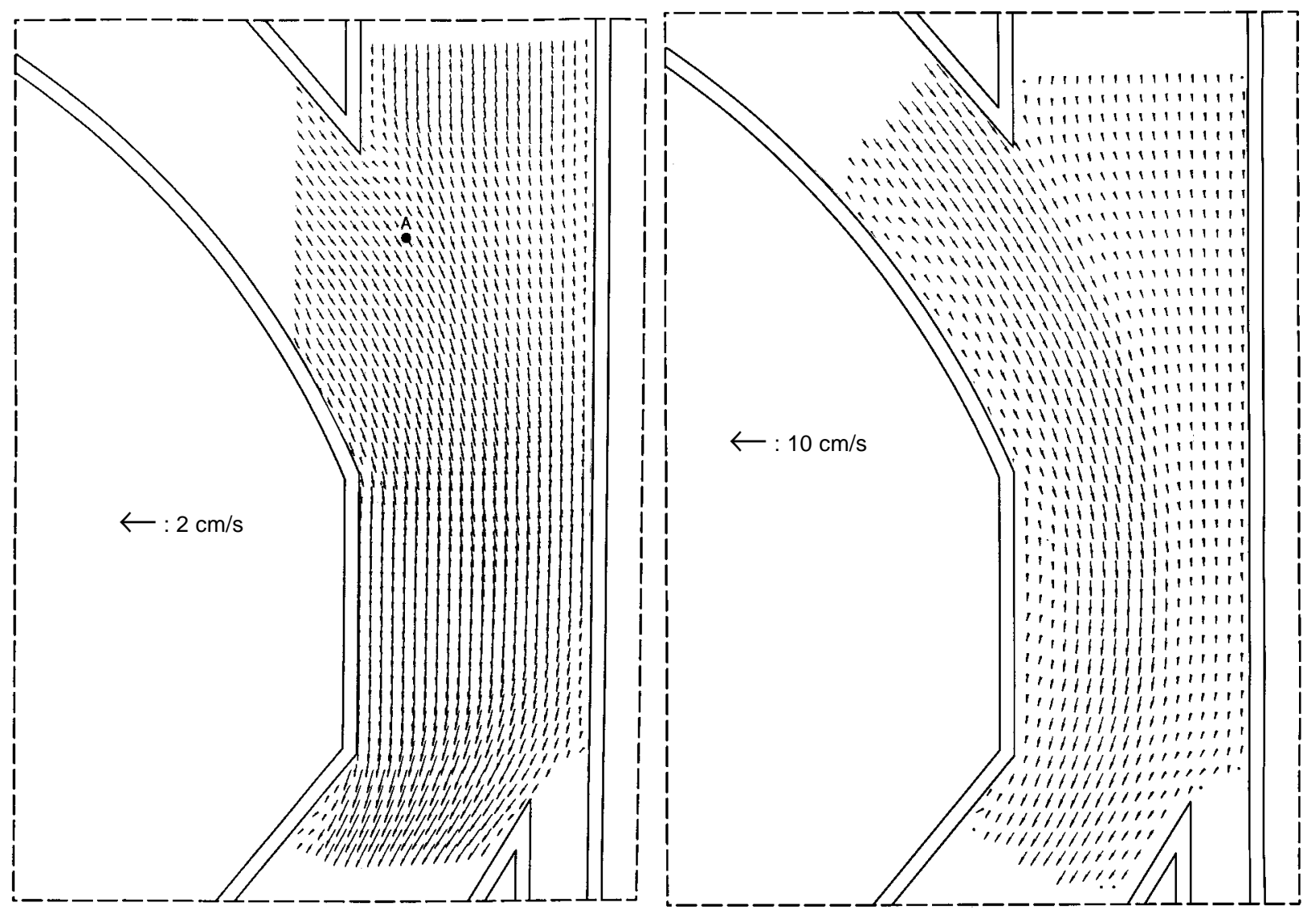

a. Average surface velocities of water flow in the confluence of rectangular channels (see Fig. 16 for an explanation of point A). b. Average surface velocities of water flow in the confluence of alluvial bed channels.

c. Instantaneous surface velocities for water flow in the confluence of rectangular channels.

Figure 14. Water surface velocities.

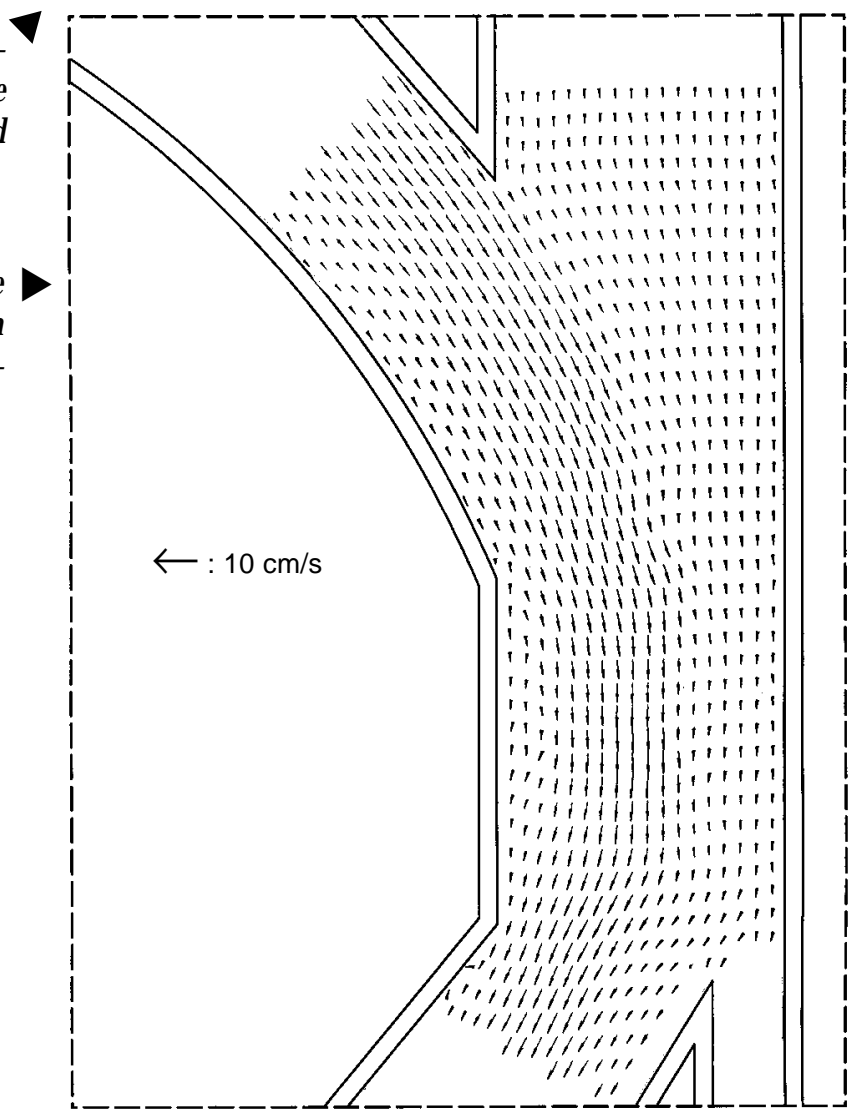




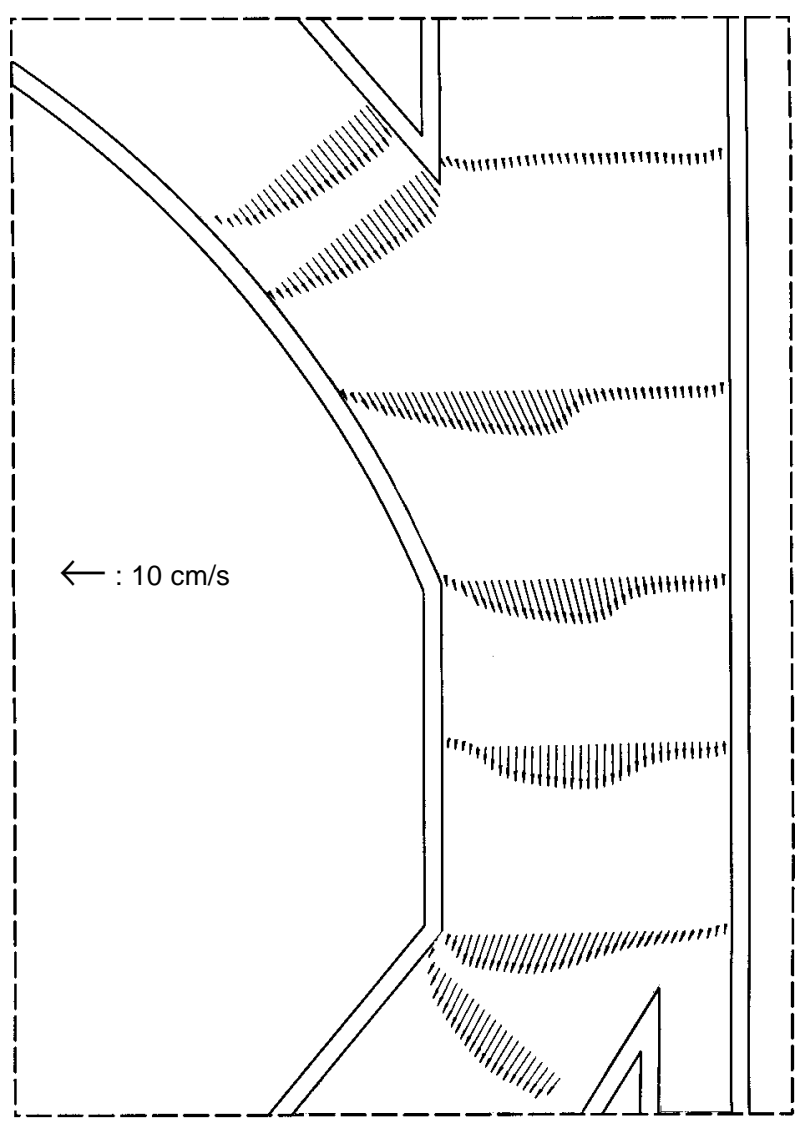

Figure 15. Cross-sectional distributions of the watersurface velocities shown in Figure 14c.

channel conditions: rectangular, alluvial-bed, and alluvial-bed with border ice. The mappings of ice movement distribution associated with those flow conditions are then presented. The data are then discussed for some implications on improvement of ice movement through the Mississippi-Missouri confluence and through confluences generally.

\section{Water velocities}

The distributions of surface velocity shown in Figure 14 demonstrate how water flows from the Mississippi and Missouri rivers merge for the three simulated channel conditions: rectangular, alluvial-bed, alluvial-bed with border ice. Figure 14a shows the velocities, averaged over 100 video frames, for flow through the rivers replicated as simple rectangular channels. Figure $14 \mathrm{~b}$ is a similar figure (also based on 100 frames) for flow through the model rivers fitted with the alluvial bed bathymetry. To show how the velocities fluctuate in the shear zone between the two flows, Figure $14 \mathrm{c}$ presents an instantaneous view of the velocities, which was taken between two video frames (i.e., about 1 second apart). The velocity fields are practically the same for Figures $14 \mathrm{~b}$ and $14 \mathrm{c}$, except that the "instantaneous" distribution reveals more of the oscillatory shear layer between the two confluent flows.

The data contained in Figure 14 can readily be manipulated and presented alternately as crosssectional distributions of velocities. Figure 15 presents cross-sectional distributions of flow for the flow field shown in Figure 14c. The measurements show that, besides its facility for mapping surficial distributions of surface velocities of water flow and ice movement, the PIV technique can produce readily usable velocity data for determining various aspects of a flow. In the present case, the measurements were analyzed further to ascertain whether PIV could capture the temporal variability in water and ice velocities attributable to lowfrequency eddies formed in the water and the ice by the confluent water flows. Figure 16 shows the temporal variation of water and ice velocities at point A (shown on Fig. 14a) located in the oscillatory shear layer formed by the two confluent flows 


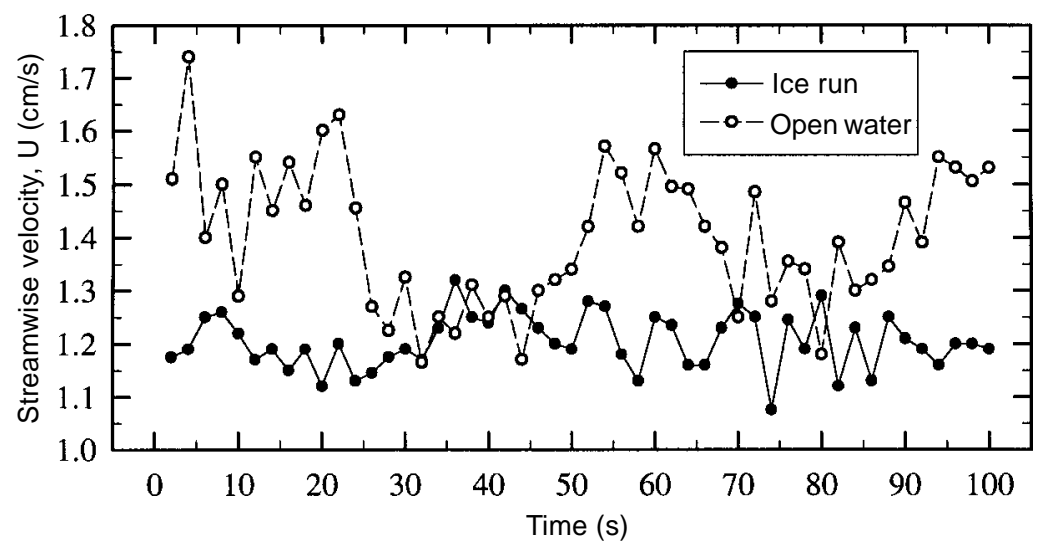

Figure 16. Temporal variation of velocities at point A in Figure 14a.

in the model. The temporal variations of velocity at a single location, as shown for point $A$, are readily obtained using PIV. It should be noted, however, that sampling frequencies in the present application of PIV were not high enough to measure small-scale turbulence fluctuations of flow velocities.

\section{Ice velocities}

Figure 17 shows how the model ice discharging from the simulated Missouri River moves through the confluence for two of the channel conditions: rectangular and alluvial-bed with border ice. Figure 17a shows ice vectors for the rectangular-channel condition. The corresponding icevelocity field for the condition in which the confluence is constricted with border ice is shown in Figure 17b. This latter figure indicates the extent of a band of ice moving through the confluence and shows how the band is deformed by the shear layer between the confluent flows. If ice thicknesses are known, local magnitudes of ice discharge are obtainable from the ice velocity distribution.

The main inference to be made from the figures is that, for the conditions modeled, ice from the Missouri River does not, on average, spread across the full width of the confluence. However, the large eddies that form in the unsteady shear zone between the merging Missouri and Mississippi flows caught ice and "flung" it across the Mississippi River. A sign of the unsteadiness of flow between the merging flows can be seen in Figure $17 \mathrm{c}$, which shows the ice-movement vectors determined between two video frames.

Figure 18 shows how the ice velocities varied across selected cross sections of the confluence, both when it was fitted with rectangular channels and when the confluence was constricted by border ice. The constriction increased model ice velocities and enlarged eddies in the shear layer formed between the merging flows of the Mississippi and Missouri rivers. Commensurate with the enlarged eddies, model ice trajectories oscillated and velocities fluctuated more markedly in the constricted confluence than in the confluence of rectangular channels. Figure 19 shows the oscillatory motions of ice at points $\mathrm{B}$ and $\mathrm{C}$ marked on Figure $17 \mathrm{~b}$. At those locations, the model ice trajectories and velocities oscillated at a period of about 0.07 seconds, which was low enough to capture using the present PIV technique. A caveat regarding the use of the PIV technique for obtaining information on oscillatory flows is that oscillation frequency should not exceed 1/60th of a second, half the frame speed of a normal CCD video camera. Frequencies up to about $4000 \mathrm{~Hz}$ can be obtained using a high-speed CCD video camera.

Values of ice discharge and its distribution are readily obtainable from Figures 14 and 17, as the model ice was known to be moving in a single piece thickness. If the model ice had formed moving, thickening accumulations, thickness measurements would have been needed in conjunction with the PIV measurements to determine ice discharge and its distribution.

The series of photographs presented in Figures 20 and 21 illustrates views of ice movement observed in the model for the conditions of rectangular channel and alluvial channel fitted with border ice.

\section{Ice transport through the confluence}

The hydraulic model indicates that ice entering the confluence from the Missouri does not 

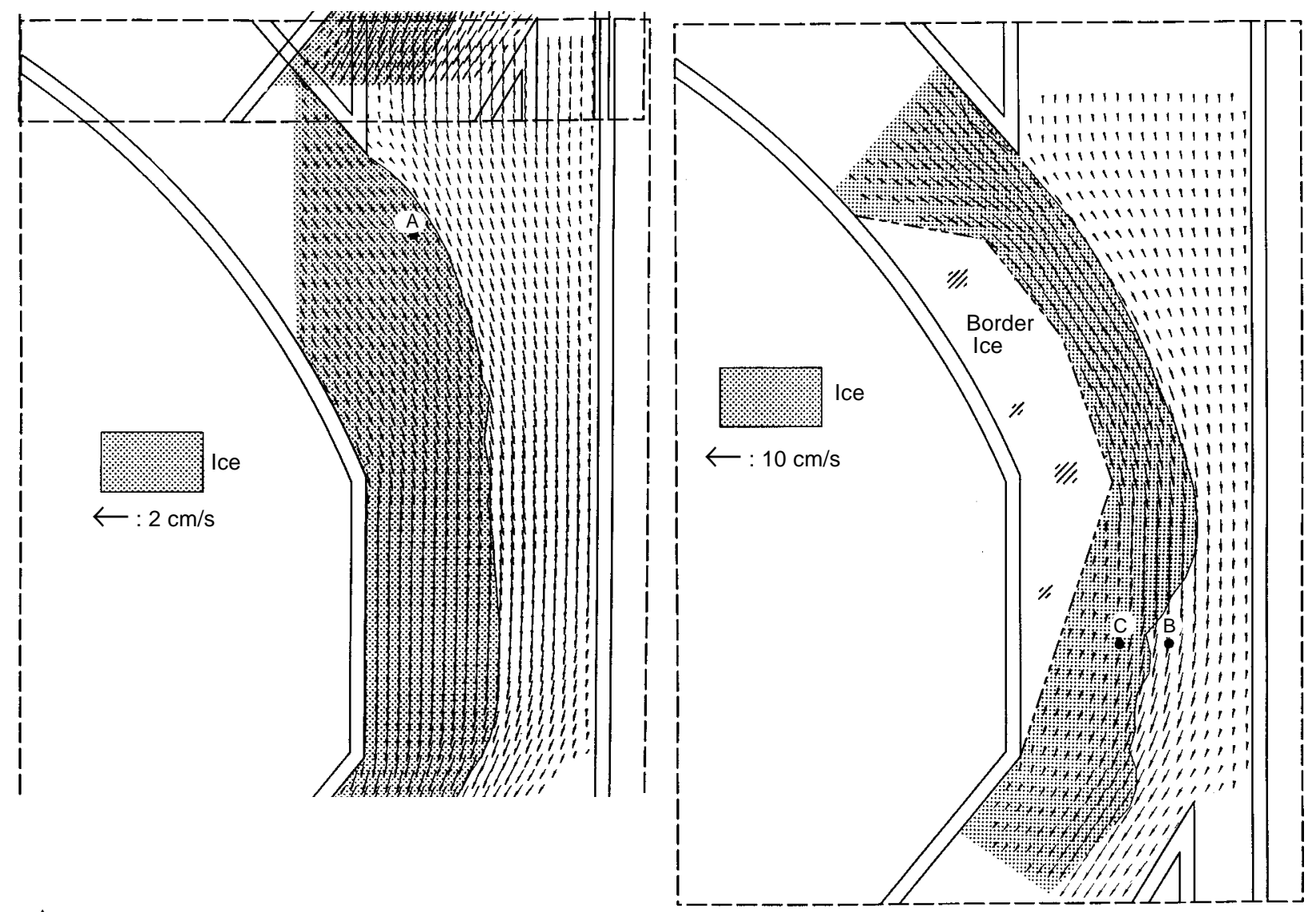

a. Average ice velocities in the confluence of rectangular channels.

b. Average ice velocities in the confluence of alluvial channels fitted with border ice constriction.

c. Instantaneous velocities in confluence of alluvial channels (see Fig. 19 for explanation of points $B$ and $\mathrm{C}$ ).

Figure 17. Ice velocities.

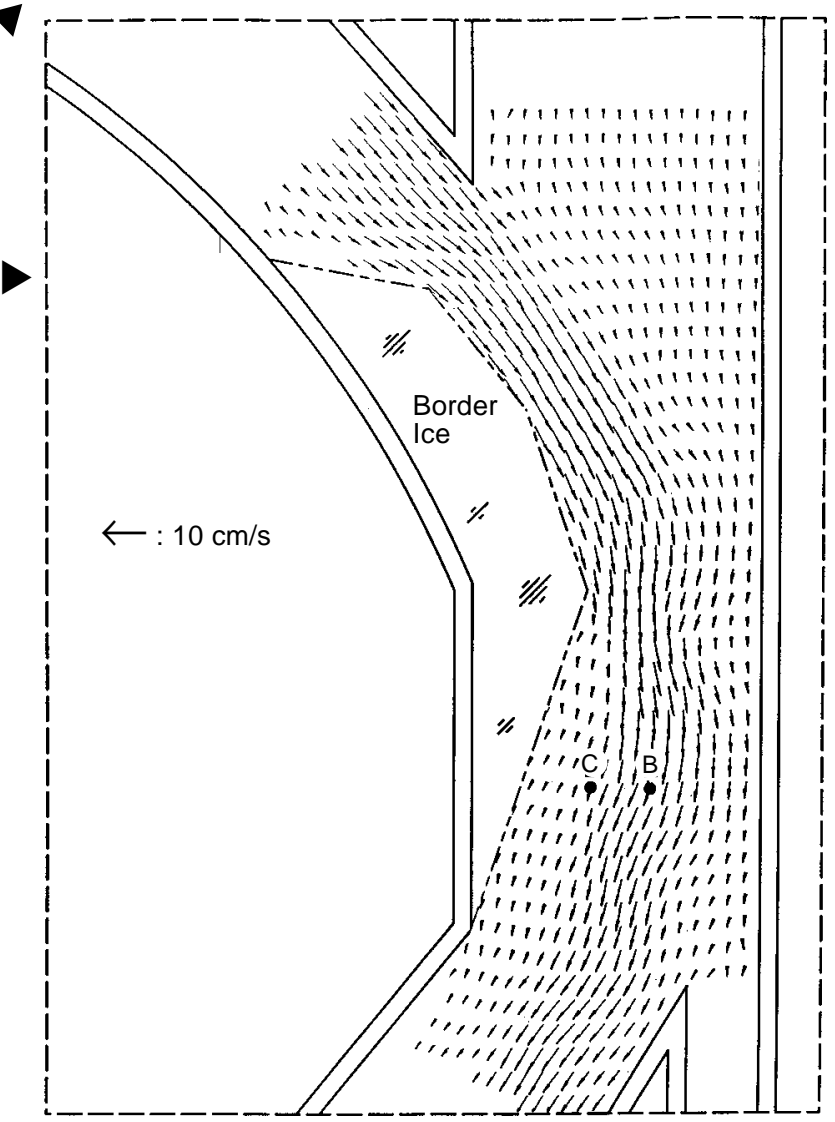




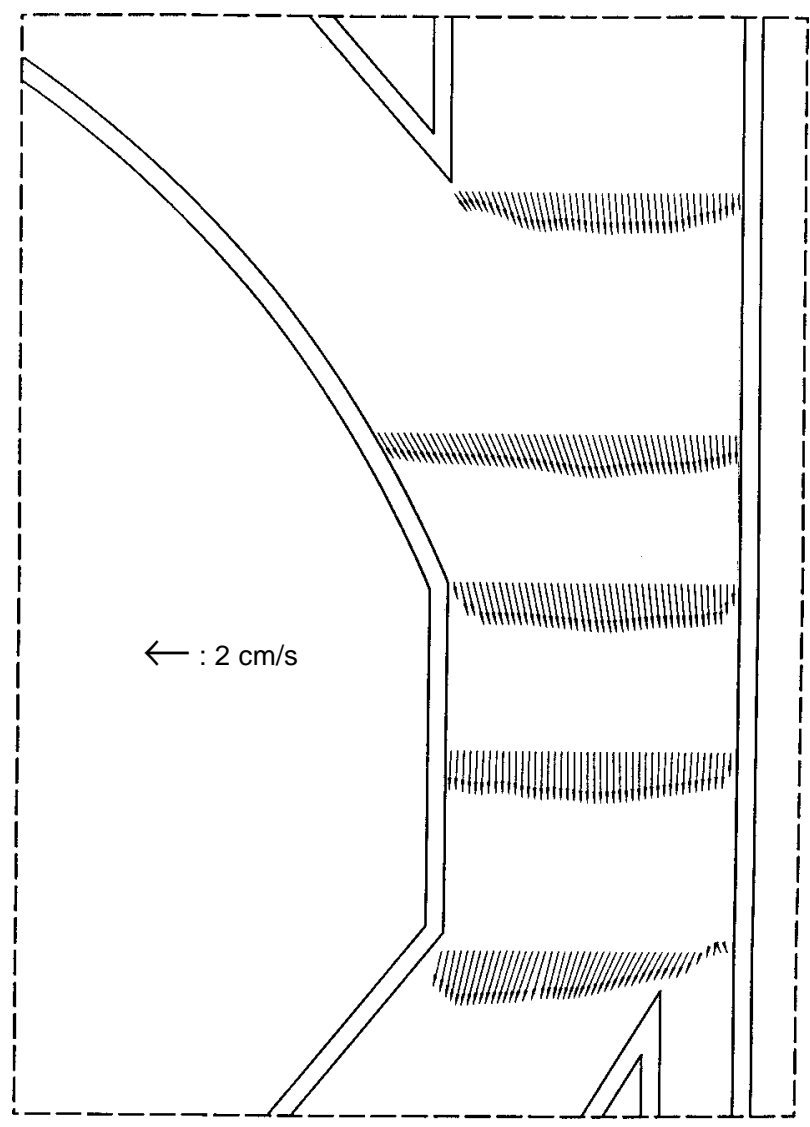

a. Rectangular channels.

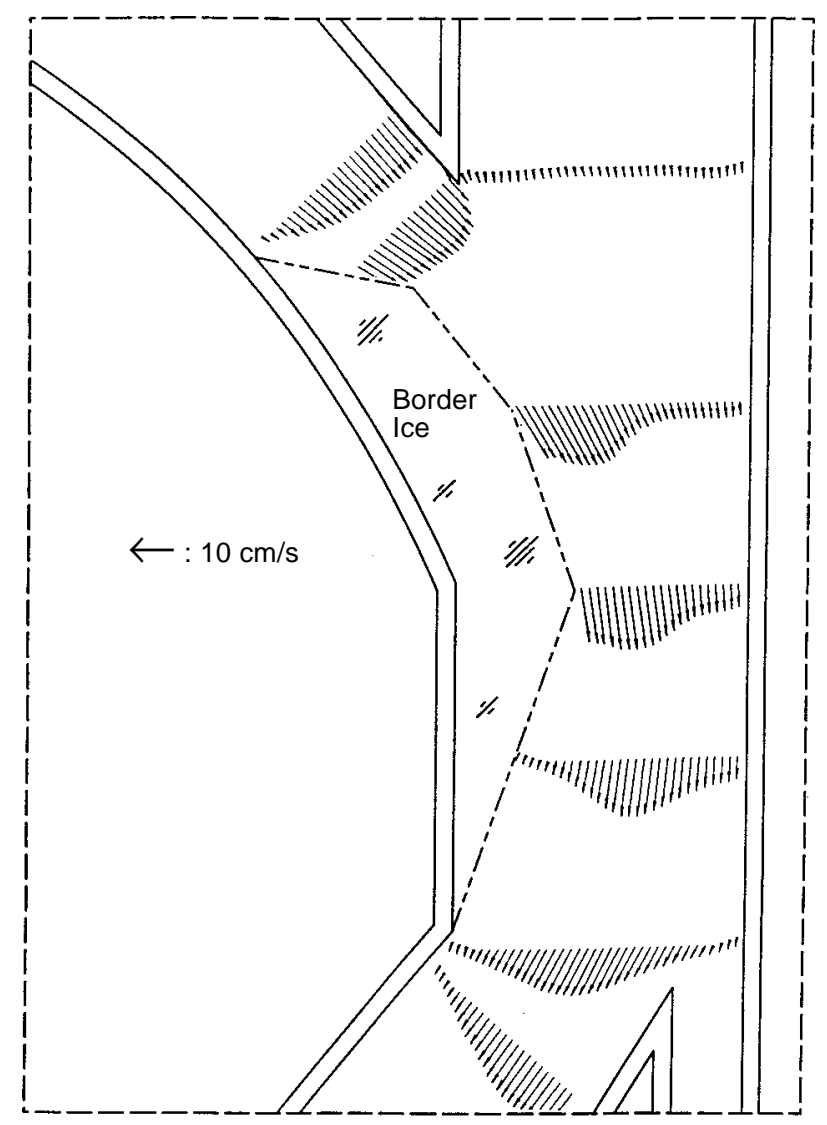

b. Alluvial channels with border ice.

Figure 18. Cross-sectional distributions of ice velocities.

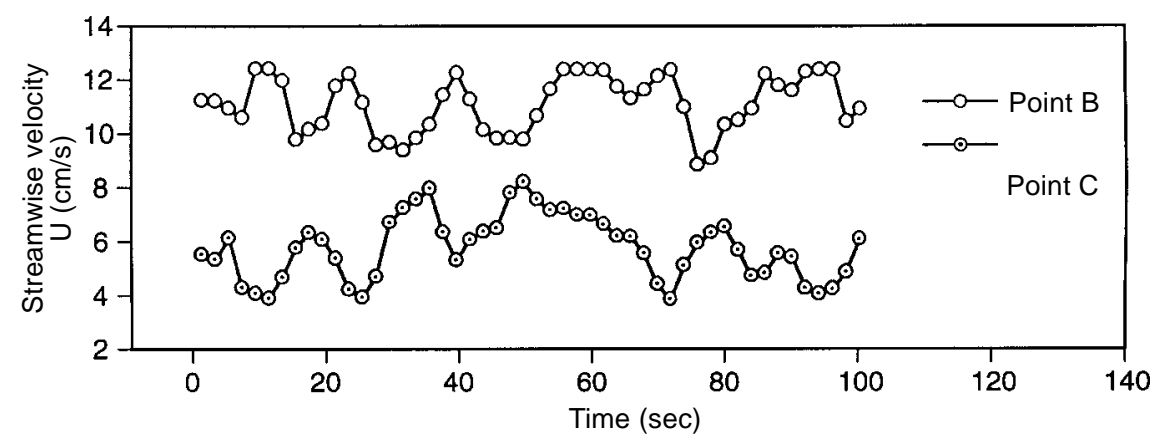

Figure 19. Temporal variations of ice velocity at points $B$ and $C$ in Figure $17 b$. 

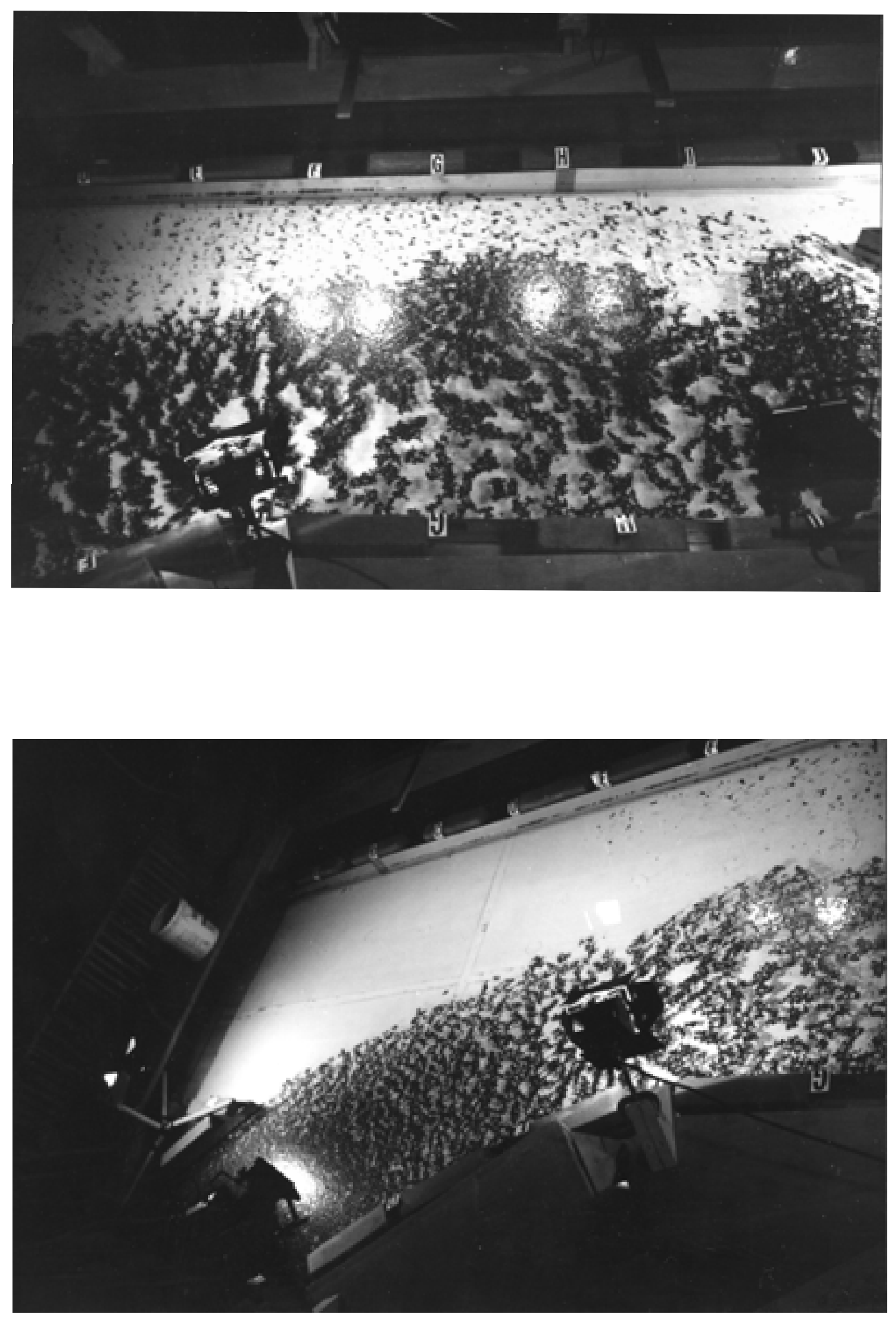

Figure 20. Two views of model ice moving through confluence of rectangular channels. 


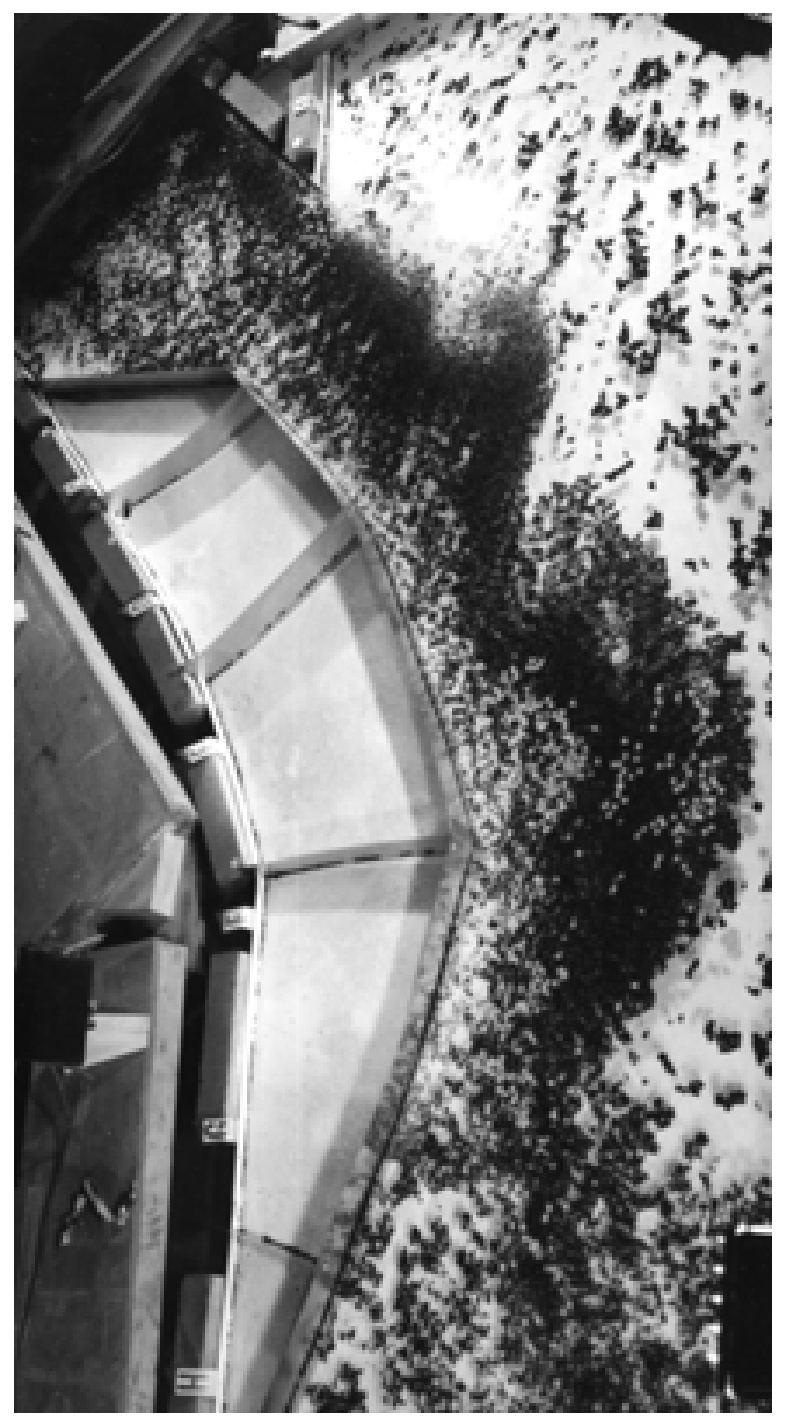

a. Low concentration of ice.

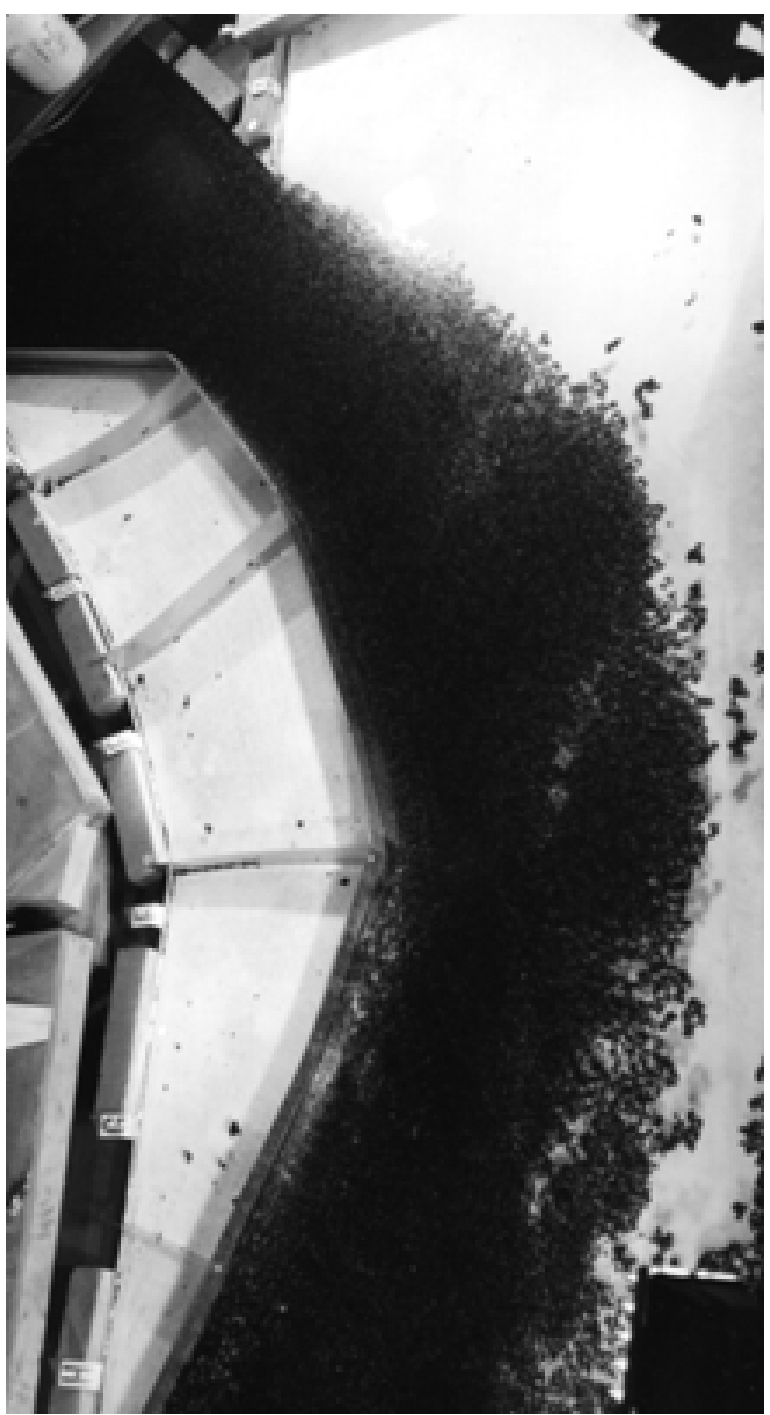

b. Moderate concentration of ice.

Figure 21. Model ice moving through the alluvial channel fitted with border ice.

sweep fully across the confluence by water currents alone, and therefore does not jam. However, field observations show that ice drifting from the Missouri River does sweep across the Mississippi River at the confluence, as Figure 22 depicts. This difference suggests that other factors need to be considered, i.e., wind, border-ice growth, bathymetric complexity, such as a large dune at the confluence, or a channel contraction downstream of the confluence. During tests, some model ice dispersed across the confluence through the action of the large eddies at the shear layer between the merging Missouri and Mississippi flows. The visible size of the eddies at the surface decreased with increasing ice discharge (or surface concentration of ice) issuing from the Missouri River. In a corresponding manner, and somewhat surprisingly, the amount of ice swept across the confluence also diminished as the areal concentration of model ice increased. Essentially, a more compact layer of moving ice increasingly damped surface eddy formation.

A related, preliminary finding is that ice discharge category I.1 probably does not lead to jamming, unless other factors, such as described above, prevail.

As wind often significantly affects ice drift in wide channels, a brief qualitative test was con- 


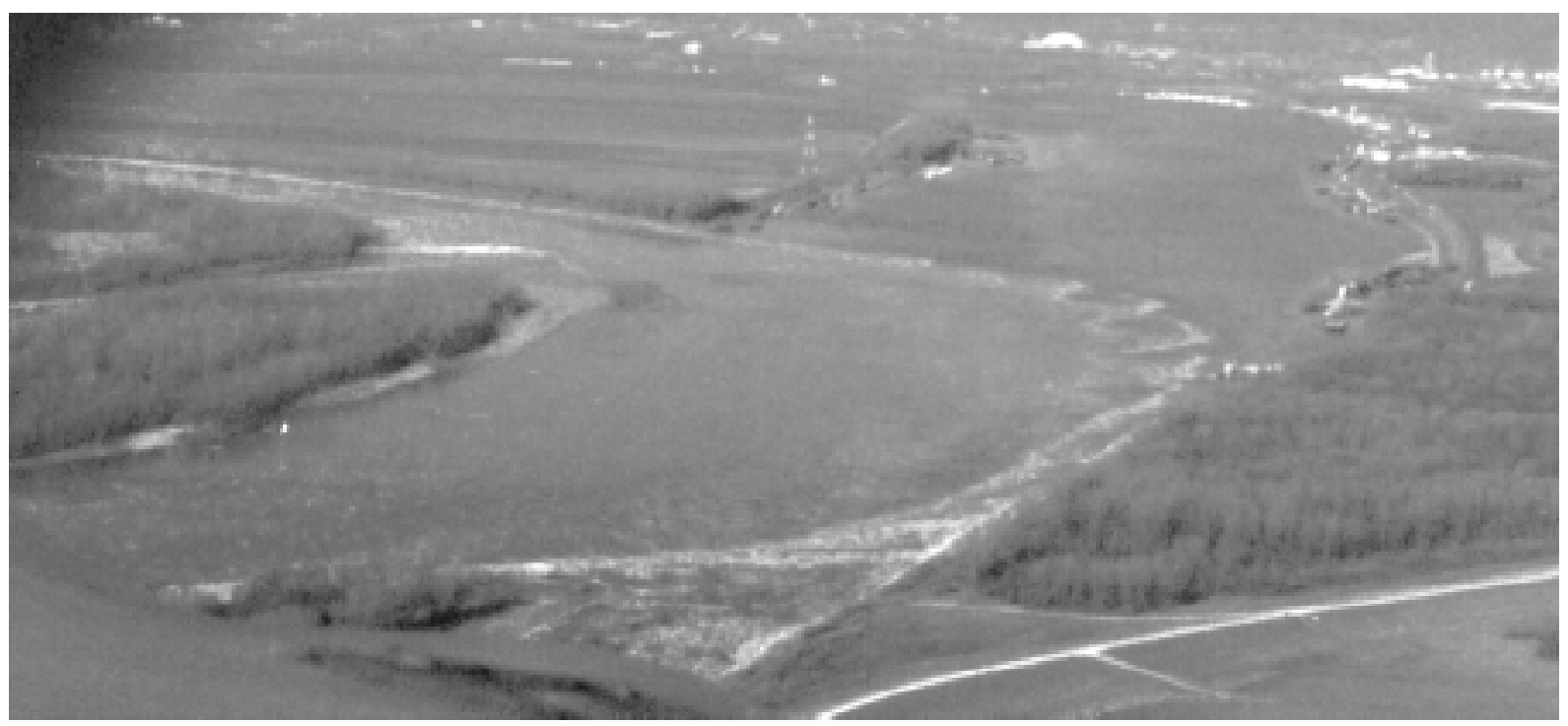

Figure 22. Ice drifting from the Missouri River across the Mississippi River at the confluence.

ducted with a fan to determine the sensitivity of drift through the confluence. An ordinary fan (0.5$m$ diameter) facing away from the confluence (i.e., facing east) drew air across the model; air was not blown onto the model. The model ice responded very quickly to the air flow, and spread fully across the confluence (Fig. 23). This simple test points out the importance of wind as a contributing factor hampering ice movement through the confluence. The wind conditions prevailing during the instances when ice jams formed at the confluence have yet to be analyzed. It is possible to conjecture that periods of ice run out of the Missouri River are accompanied by westerly or northwesterly winds. The basis for this conjecture, to be substantiated, is that the ice discharging from the Missouri River is predominantly frazil ice formed when cold weather descends from the northwest.

A number of implications arise from the foregoing observations:

- It would seem that difficulties in ice movement through the Mississippi-Missouri confluence stem from the combined actions of water current and wind, as well as the amount of ice discharged.

- It appears at this stage that, if wind is important, flow modifications alone (e.g., channel realignment, blockage of the small channel behind the point-bar [evident in Fig. 8]) may not sufficiently enhance ice movement through the confluence.

- Numerical modeling will be needed to quan- titatively gauge the relative importances of water current and wind for ice movement through wide confluences, such as the Mississippi-Missouri confluence.

- Numerical modeling, though useful for simulating "average" distributions of flow and ice movement, will not be able to simulate the detailed action of eddies in the shear zone between confluent flows.

- At this point in the study, it appears that the severe ice stoppages in the MississippiMissouri confluence predominantly occur when ice discharges from the Missouri River. Tentative observations (not fully documented here) suggest that greater release of water from the Mississippi River likely does not adversely affect ice movement through the confluence.

An observation specific to the Missouri River is its propensity to jam a short distance upstream of the confluence-during most tests, a full width, single-layer thickness of model ice slowed and occasionally stopped in the reach shown in Figure 24. The reach, in effect, limits the amount of ice that the Missouri can convey into the confluence. With regard to the Missouri-Mississippi confluence, the results suggest that consideration might be given to determining the requirements for increasing the ice-discharge capacity of the river at the location indicated in Figure 24. However, increasing the ice-discharge capacity of the Missouri River may lead to jamming in the Mississippi River 
Figure 23. Effect of simulated wind over the confluence. Wind direction is approximately northwesterly (diagonally across the confluence).

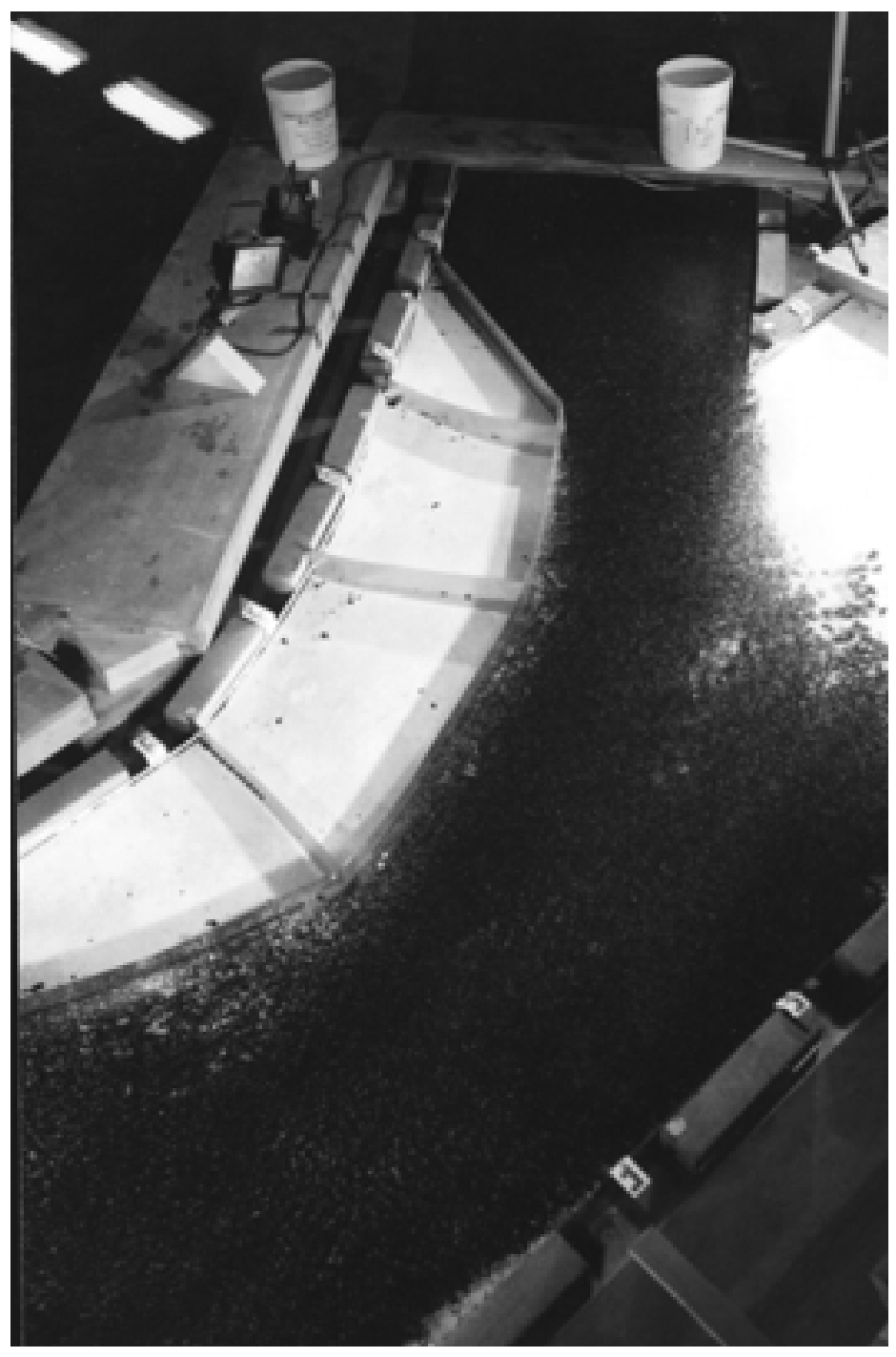

immediately downstream of the confluence, and this must be taken into consideration.

\section{CONCLUSIONS}

Three sets of preliminary conclusions can be drawn from the results of this study. One set relates to the confluence conditions that seem to be typically associated with ice jam development at confluences. The second set relates to the investigation of ice discharge processes through river confluences, with particular attention given to the confluence of the Missouri and Mississippi rivers as a case study. The third set concerns the use of PIV for mapping water and ice velocities.

\section{Confluence conditions causing jams}

It appears, at this stage, that a major proportion of jam problems at confluences are attributable to two causes:

- Ice from one channel discharges into a channel that has a sluggish flow (a lake is a limiting example of this situation) or has a stationary ice cover.

- Bathymetric irregularities in confluence geometry retard ice discharge and initiate jams.

Jams caused by the merging of ice discharged from two confluent channels may occur less frequently, since the joint probability of ice discharging from two channels simultaneously is likely to be small. Further work should address two specific objectives. One is to determine the conditions 


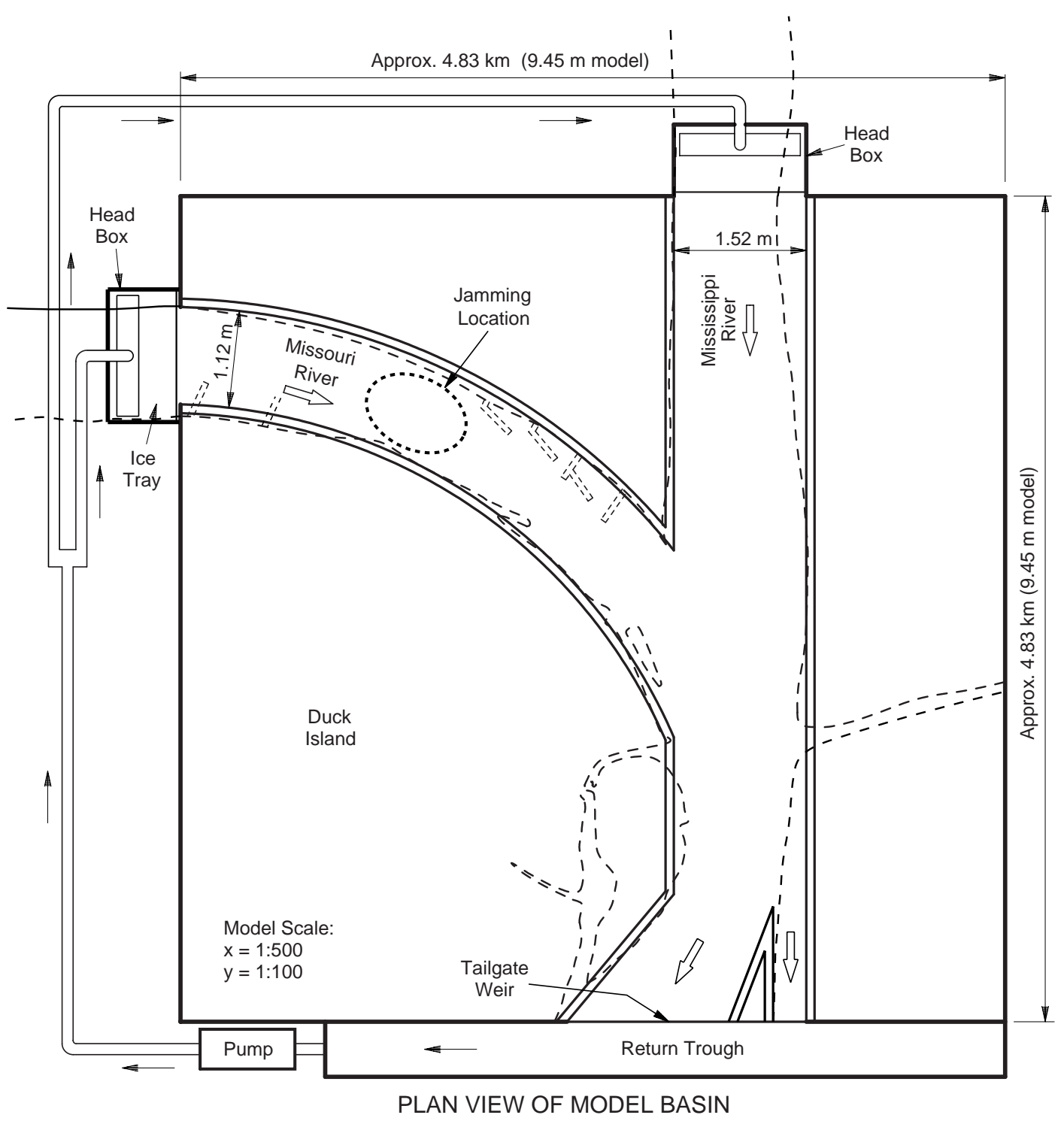

Figure 24. Tentative location of incipient jamming observed in the modeled Missouri River.

needed for two confluent ice discharges to jam. Attaining this objective entails doing parametric experiments to evaluate the jamming limits of the more important parameters identified in eq 7 and 12. The second objective is to determine the processes whereby ice (from one or two channels) moves through a confluence, and to assess how confluence bathymetry and border ice growth may substantially hamper ice discharge.

\section{Ice discharge through the confluence of the Missouri and Mississippi rivers}

The hydraulic model suggests that some form of bathymetric irregularity or combination of flow obstructions, such as a large dune and border-ice growth, causes ice jams at the confluence. Wind, too, may have a significant effect. Ice discharged from the Missouri River, without the aforementioned irregularity or obstructions, does not jam at the confluence. Ice may jam in the Missouri River at a short distance upstream of the confluence, however. Future study of bathymetric effects and border ice growth is warranted.

\section{PIV for mapping ice velocities}

The preliminary work with the hydraulic model proves the utility of PIV for determining wholefield velocities of water and model ice movement in the hydraulic model. This finding, together with successful application of PIV for determining sur- 
face currents on a river (Fujita and Komura 1994, Aya et al. 1995), points out that PIV holds great promise for use in determining ice velocities for a wide range of field situations, e.g., ice runs in complex river channels. It would be a useful adjunct to various forms of remote sensing of ice movement. The method can be used with video, photographic, or radar images of ice movement, provided the field of view and the period between images facilitates the pattern-interrogation procedure at the heart of the method. Additionally, PIV could be essential for calibrating and validating numerical models of ice movement in diverse situations.

The principal utility of PIV for determining ice velocities is its ability to produce detailed, whole-field information that can readily be used to interpret the spatial and temporal evolutions of moving fields of ice. PIV could also be used to determine concentrations and discharge rates (if ice thickness were known) of moving ice, though that facility of PIV was not examined here.

\section{LITERATURE CITED}

Adrian, R.J. (1991) Particle-imaging techniques for experimental fluid mechanics. Annual Review of Fluid Mechanics, 23: 261-304.
Ashton, G.D. (Ed.) (1986) River and Lake Ice Engineering. Littleton, Colorado: Water Resources Publications.

Aya, S., I. Fujita, and M. Yagyu (1995) Fieldobservation of flood in a river by video image analysis. Proceedings of Hydraulic Engineering, JSCE, 39: 447-452.

Dobrowolski, A., A. Kondzielski, and B. Glowack (1992) Operational using of video technique for assessment of ice transport in Middle Vistula River. Proceedings, Conference on Application of Remote Sensing in Operational Hydrology. Cracow University of Technology, Institute of Water Engineering and Water Management, Cracow, Poland. Fujita, I., and S. Komura (1994) Application of video image analysis for measurements of riversurface flows. Proceedings of Hydraulic Engineering, JSCE, 38: 733-738.

Murthy, P. (1991) Computerized hydraulic modeling. Proceedings, ASCE Hydraulic Engineering Conference, Nashville, Tennessee, pp. 786-791.

Pickering, C. J. D., and N. A. Halliwell (1991) Speckle photography in fluid flows: Signal recovery with two-step processing. Applied Optics, 23: 1128-29.

Tuthill, A.M., and A.C. Mamone (1997) Selection of confluence sites with ice problems for structural solutions. U.S. Army Cold Regions Research and Engineering Laboratory, Special Report 97-4. 


\section{REPORT DOCUMENTATION PAGE}

Public reporting burden for this collection of information is estimated to average 1 hour per response, including the time for reviewing instructions, searching existing data sources, gathering and maintaining the data needed, and completing and reviewing the collection of information. Send comments regarding this burden estimate or any other aspect of this collection of information, including suggestion for reducing this burden, to Washington Headquarters Services, Directorate for Information Operations and Reports, 1215 Jefferson Davis Highway, Suite 1204, Arlington, VA 22202-4302, and to the Office of Management and Budget, Paperwork Reduction Project (0704-0188), Washington, DC 20503.

\begin{tabular}{|l|l|l}
\hline 1. AGENCY USE ONLY (Leave blank) & $\begin{array}{l}\text { 2. REPORT DATE } \\
\text { December } 1997\end{array}$ & 3. REPORT TYPE AND DATES COVERED
\end{tabular}

4. TITLE AND SUBTITLE

5. FUNDING NUMBERS

Factors Influencing Ice Conveyance at River Confluences

CWIS

WU: 33024

\section{AUTHORS}

Robert Ettema, Marian Muste, Anton Kruger, and Jon Zufelt

7. PERFORMING ORGANIZATION NAME(S) AND ADDRESS(ES)

8. PERFORMING ORGANIZATION REPORT NUMBER

Iowa Institute of Hydraulic Research U.S. Army Cold Regions Research and

The University of Iowa

Iowa City, Iowa 52242-1585

Engineering Laboratory

72 Lyme Road

Hanover, New Hampshire 03755

9. SPONSORING/MONITORING AGENCY NAME(S) AND ADDRESS(ES)

10. SPONSORING/MONITORING AGENCY REPORT NUMBER

Office of the Chief of Engineers

Washington, D.C. 20314-1000

11. SUPPLEMENTARY NOTES

For conversion of SI units to non-SI units of measurement, consult ASTM Standard E380-93, Standard Practice for Use of the International System of Units, published by the American Society for Testing and Materials, 1916 Race St., Philadelphia, Pa. 19103.

12a. DISTRIBUTION/AVAILABILITY STATEMENT

12b. DISTRIBUTION CODE

Approved for public release; distribution is unlimited.

Available from NTIS, Springfield, Virginia 22161

13. ABSTRACT (Maximum 200 words)

This report documents preliminary findings concerning ice jam conditions in river confluences, using two laboratory approaches. First is categorizing the different conditions of ice discharge into a confluence based on two general classifications: free drift of ice and movement of contiguous ice accumulations. The variables defining ice discharge for the two categories are assembled via dimensional analysis into two consistent sets of nondimensional parameters. The categorization, together with the nondimensional parameters, is used to evaluate ice jam problems at confluences-the two most common causes of jams seem to be sluggish water velocities in the outflow channel and local bathymetric features. The second approach examines how confluence geometry and flow processes affect ice discharge-for example, the influence on ice discharge of bathymetric features. The approach uses a large hydraulic model of a two-channel confluence, which is adaptable to a variety of channels, and particle image velocimetry (PIV) for determining and mapping whole fields of water and ice velocities in a confluence. PIV, which is becoming extensively used, lends itself very well here. This study is the first demonstration of the PIV method for ice movement through a two-river confluence. It shows promise. The hydraulic model and PIV method are used in a case study of ice discharge through the confluence of the Missouri and Mississippi rivers, a confluence prone to severe ice jams.

\begin{tabular}{|c|c|c|c|c|c|}
\hline \multirow[t]{2}{*}{ 14. SUBJECT TERMS } & \multirow{2}{*}{\multicolumn{2}{|c|}{$\begin{array}{l}\text { Confluence } \\
\text { Dimensional analysis }\end{array}$}} & \multirow{2}{*}{\multicolumn{2}{|c|}{$\begin{array}{l}\text { Hydraulic model } \\
\text { Ice jam }\end{array}$}} & $\begin{array}{l}\text { 15. NUMBER OF PAGES } \\
38\end{array}$ \\
\hline & & & & & 16. PRICE CODE \\
\hline \multicolumn{2}{|c|}{$\begin{array}{l}\text { 17. SECURITY CLASSIFICATION } \\
\text { OF REPORT }\end{array}$} & \multicolumn{2}{|c|}{$\begin{array}{l}\text { 18. SECURITY CLASSIFICATION } \\
\text { OF THIS PAGE }\end{array}$} & $\begin{array}{l}\text { 19. SECURITY CLASSIFICATION } \\
\text { OF ABSTRACT }\end{array}$ & 20. LIMITATION OF ABSTRACT \\
\hline \multicolumn{2}{|c|}{ UNCLASSIFIED } & \multicolumn{2}{|c|}{ UNCLASSIFIED } & UNCLASSIFIED & UL \\
\hline
\end{tabular}

